\title{
E-region decameter-scale plasma waves observed by the dual TIGER HF radars
}

\author{
B. A. Carter and R. A. Makarevich \\ Department of Physics, La Trobe University, Bundoora, Victoria 3086, Australia \\ Received: 5 May 2008 - Revised: 19 November 2008 - Accepted: 4 December 2008 - Published: 15 January 2009
}

\begin{abstract}
The dual Tasman International Geospace Environment Radar (TIGER) HF radars regularly observe E-region echoes at sub-auroral magnetic latitudes $58^{\circ}-60^{\circ} \mathrm{S}$ including during geomagnetic storms. We present a statistical analysis of E-region backscatter observed in a period of $\sim 2$ years (late 2004-2006) by the TIGER Bruny Island and Unwin HF radars, with particular emphasis on storm-time backscatter. It is found that the HF echoes normally form a $300-\mathrm{km}$-wide band at ranges $225-540 \mathrm{~km}$. In the evening sector during geomagnetic storms, however, the HF echoes form a curved band joining to the F-region band at $\sim 700 \mathrm{~km}$. The curved band lies close to the locations where the geometric aspect angle is zero, implying little to no refraction during geomagnetic storms, which is an opposite result to what has been reported in the past. The echo occurrence, Doppler velocity, and spectral width of the HF echoes are examined in order to determine whether new HF echo types are observed at sub-auroral latitudes, particularly during geomagnetic storms. The datasets of both TIGER radars are found to be dominated by low-velocity echoes. A separate population of storm-time echoes is also identified within the datasets of both radars with most of these echoes showing similar characteristics to the low-velocity echo population. The stormtime backscatter observed by the Bruny Island radar, on the other hand, includes near-range echoes $(r<405 \mathrm{~km})$ that exhibit some characteristics of what has been previously termed the High Aspect angle Irregularity Region (HAIR) echoes. We show that these echoes appear to be a storm-time phenomenon and further investigate this population by comparing their Doppler velocity with the simultaneously measured F- and E-region irregularity velocities. It is suggested that the HAIR-like echoes are observed only by HF radars with relatively poor geometric aspect angles when electron density is low and when the electric field is particularly high.
\end{abstract}

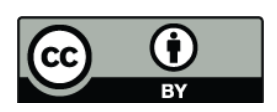

Correspondence to: R. A. Makarevich (r.makarevich@latrobe.edu.au)
Keywords. Ionosphere (Ionospheric irregularities; Plasma waves and instabilities) - Magnetospheric physics (Storms and substorms)

\section{Introduction}

Coherent radar backscatter from plasma irregularities in the auroral ionosphere, also known as radar aurora, is an important high-latitude phenomenon. Radar aurora is often used to monitor and study large-scale processes in the ionosphere and magnetosphere, such as global plasma convection, magnetosphere-ionosphere coupling, and geomagnetic storms. Consequently, much emphasis has been given to understanding why and where the irregularities occur and what the favourable conditions for their generation are.

In the E region (100-120 km altitude), the bulk of plasma irregularities are believed to be generated by either the modified two-stream instability also known as the FarleyBuneman instability (FBI) or the gradient-drift instability (GDI) (e.g. review by Fejer and Kelley, 1980). The irregularities are strongly magnetic-field-aligned as the FBI and GDI are strongly damped in the directions outside of a small cone of angles around perpendicular to the magnetic field (aspect angles $\alpha<\sim 1^{\circ}$ ). The FBI waves are also generated at relatively small angles with respect to the plasma drift direction (flow angles $\theta<\sim 50^{\circ}$ ) with the instability growth rate maximized along the flow at $\theta=0^{\circ}$. Strong narrow spectra centered near the typical values for the ion acoustic speed $C_{s}$ in the E-region $(350-450 \mathrm{~m} / \mathrm{s})$, termed Type I echoes, were experimentally shown to occur at small flow and aspect angles and hence were directly associated with the FBI. Wider and weaker spectra with near-zero Doppler velocity, termed Type II echoes, were also identified and attributed to the primary and secondary GD waves (see review by Haldoupis, 1989).

On a more global scale, strong electric fields ( $>20 \mathrm{mV} / \mathrm{m}$ ) are needed to produce Type I echoes, while Type II echo

Published by Copernicus Publications on behalf of the European Geosciences Union. 
generation requires substantial electron density gradients (Fejer and Kelley, 1980). The enhanced electric fields and electrojet currents are often observed during periods of geomagnetic disturbances and the radar aurora at meter and centimeter scales has been shown to collocate with these enhancements (e.g. Greenwald et al., 1975).

A large database of observations has been compiled over several decades using VHF and UHF radars stationed in various parts of the world (Fejer and Kelley, 1980; Hanuise, 1983; Haldoupis, 1989; Sahr and Fejer, 1996). Most studies have concentrated on the equatorial and auroral observations while irregularities at sub-auroral latitudes still remain less investigated (Fejer and Kelley, 1980; Hanuise, 1983). This is despite some suggestions that the sub-auroral irregularities may differ significantly from their auroral counterparts in their properties and generation mechanisms (e.g. Meyer et al., 2004).

Significant differences have also been shown to exist between the echo characteristics at different wavelengths/radar frequencies (Moorcroft, 2002). The decameter-scale waves are studied using various HF radar systems with the radars of the Super Dual Auroral Radar Network (SuperDARN) playing an important role by providing the bulk of auroral observations at HF (Chisham et al., 2007). The differences between the waves at different scales have also been studied by comparing the datasets collected by the radar systems in different times and different places (Eglitis et al., 1995; Moorcroft, 2002), as well as by employing nearly simultaneous and coincident double- and multi-frequency observations (Makarevitch et al., 2001, 2002a,b; Koustov et al., 2002; Milan et al., 2003).

The HF echoes appear to exhibit different spectral characteristics from VHF and UHF echoes. Hanuise et al. (1991) conducted a statistical study of HF echoes using the Système HF d'Etudes Radar Polaries et Aurorales (SHERPA) radar at high latitudes. These authors observed echoes that were reminiscent of both Type I and II echoes with the exception of substantially smaller spectral widths. No other spectral types were present throughout a wide range of geomagnetic conditions. Similarly, Haldoupis et al. (1996) found both Type I and Type II echoes as detected using a HF radar at mid-latitudes. Milan and Lester (2001) used the SuperDARN Iceland East HF radar to classify all E-region echoes into 5 spectral populations. Two of these populations exhibited properties similar to Types I and II and were therefore attributed to the FBI and GDI, respectively. The other 3 populations had Doppler velocities over a large range of values, with some echoes exhibiting velocities largely exceeding the nominal $C_{s}$ values of $350-450 \mathrm{~m} / \mathrm{s}$. Large E-region velocities of up to $700 \mathrm{~m} / \mathrm{s}$ were also reported by Makarevitch et al. (2002a) using the SuperDARN Syowa East radar in Antarctica. On the other hand, Makarevitch et al. (2002a) identified only 2 populations of high- and low-velocity echoes reminiscent of classical Type I and Type II echoes.
The location of HF echoes in slant range has been shown to depend strongly on ionospheric refraction and on geomagnetic activity level. Thus Koustov et al. (2001) and Makarevitch et al. (2002a) compared the echo band locations in the morning sector at VHF and HF using two SuperDARN HF radars and one VHF radar at Syowa. The HF echoes were found to occur closer to the radar than their VHF counterparts, which was most likely due to greater refraction experienced by the HF waves. Similarly, Ogawa et al. (2002) used the SuperDARN Syowa East HF radar to examine spatial occurrence patterns during periods of increased geomagnetic storm activity. They found that with increasing storm activity echo ranges shortened due to enhanced radar wave refraction caused by increased electron density in the D- and E-regions.

In this paper, we statistically investigate the E-region backscatter using the Tasman International Geospace Environment Radar (TIGER) system of dual HF radars. The recent addition of this most equatorward HF radar pair in the SuperDARN array presents an excellent opportunity to study decameter-scale E-region echoes at sub-auroral latitudes, in particular during storm conditions when the radar aurora expands equatorward. As will be shown in Sect. 2.1, the aspect angle conditions for the detection of E-region backscatter by the TIGER radars are quite favourable; that is no significant refraction is required to achieve orthogonality with the local magnetic field in the near field-of-view (FoV). Consequently, one can expect the E-region echoes to be observed under a wide range of ionospheric conditions. This experimental configuration is characterised by favourable and similar aspect angle conditions for both radars, as well as by the close proximity between the expected locations of Eregion backscatter for the two radars. This provides an excellent opportunity to study the E-region plasma irregularities for different L-shell angle ranges (and hence different flow angle regimes) by comparing the observations from the two TIGER radars. The specific objectives are: (1) to determine the typical and storm-time spatial occurrence patterns of decameter-scale echoes at sub-auroral latitudes, (2) to investigate the occurrence dependence on the flow and aspect angles, and (3) to determine whether new types of HF echoes occur at sub-auroral latitudes, in particular during geomagnetic storms and, if so, investigate the conditions favourable for their detection.

\section{Observations}

\subsection{Experimental setup and data analysis}

The dual TIGER system (Dyson and Devlin, 2000; Makarevich and Dyson, 2007) consists of two HF coherent backscatter radars with overlapping FoVs in the Southern Ocean, Fig. 1. The two radars are located on Bruny Island, Tasmania, Australia $\left(43.38^{\circ} \mathrm{S}, 147.23^{\circ} \mathrm{E}\right.$, geographic) and on the South Island of New Zealand $\left(46.51^{\circ} \mathrm{S}, 168.38^{\circ} \mathrm{E}\right.$, 
geographic) and are hereinafter referred to as the Bruny Island and Unwin radars, respectively. The dual TIGER system is the most equatorward pair in the SuperDARN array of analogous HF radars (Greenwald et al., 1995; Chisham et al., 2007). Each TIGER radar (like all other SuperDARN radars) has 16 azimuthal beam directions separated by $\sim 3.25^{\circ}$ that form a $\sim 52^{\circ}$-wide FoV. The radars operate at frequencies between 8-20 MHz. For each beam, the radars sample 75 range gates normally separated by $45 \mathrm{~km}$ with the first range gate of $180 \mathrm{~km}$. The radars scan from beam 0 to beam 15 with the total scan time of $2 \mathrm{~min}$ (common mode) or $1 \mathrm{~min}$ (fast mode). The data analysed in this study were obtained whilst the TIGER radars operated either in common or fast modes.

The data considered in this study were taken between November 2004 and December 2006 whilst both radars were in operation. All spectral parameters were obtained using the standard FITACF algorithm (Ponomarenko and Waters, 2006). Ground- and sea-scatter echoes were removed from the dataset using the standard SuperDARN criteria of low width and velocity. The ionospheric dataset was cleaned by excluding echoes with low power $(\mathrm{SNR}<3 \mathrm{~dB})$ and/or large spectral widths $(W>500 \mathrm{~m} / \mathrm{s})$. The HF echoes detected at large ranges $(r>765 \mathrm{~km})$ were also excluded as these are likely to originate from the F-region (Hanuise et al., 1991; Milan and Lester, 2001; Makarevitch et al., 2002a). The short-range parts of the FoV $(r \leq 765 \mathrm{~km})$, the data from which were considered in this study, are shown by the dark blue sectors in Fig. 1.

To eliminate possible contamination from interference, noise and meteors, several additional criteria were set. Data in any specific radar cell were entered into a database only (1) if there was at least 1 echo detected in either an adjacent slant range bin or an adjacent beam and (2) if there was at least 1 echo detected in this radar cell in either the previous or following scan. In addition, all echoes with small velocities and widths $(V<40 \mathrm{~m} / \mathrm{s}$ and $W<30 \mathrm{~m} / \mathrm{s})$ were excluded. The former group of criteria is similar to those employed previously by Fukumoto et al. (1999) and by Makarevitch et al. (2001, 2002b), whereas the latter is based on the characteristics of meteor echoes reported by Hall et al. (1997).

As explained in Sect. 1, the E-region echoes are expected to occur at nearly perfect aspect angles $\left(\alpha=0^{\circ}\right)$. Figure 1 shows the lines of equal geometric (rectilinear) aspect angles, $\alpha=-1^{\circ}, 0^{\circ}$ and $+1^{\circ}$, calculated at an altitude of $110 \mathrm{~km}$, as the red, orange, and yellow circular lines, respectively. Also, the lines of real aspect angle $\alpha_{R}=0^{\circ}$ at $110 \mathrm{~km}$ were calculated using a model electron density profile with a peak electron density of $4 \times 10^{4} \mathrm{~cm}^{-3}$. The expected real aspect angles were calculated using the geometric optics approach of Uspensky et al. (1994); they are shown by the green lines in Fig. 1. The breaks in the geometric aspect angle lines are a numerical artefact; the aspect angles are nearly constant along these tangential directions. One can expect that the echoes will occur close to the locations given by these lines in the absence of significant radio wave refraction. As the elec-

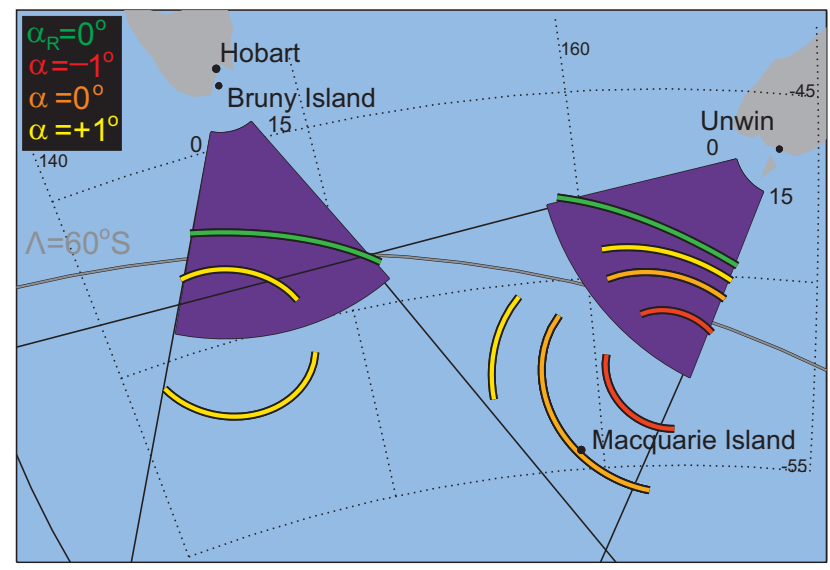

Fig. 1. The positions and the near fields-of-view (FoVs) of the TIGER Bruny Island and Unwin radars. Beam $0(15)$ is the westernmost (easternmost) beam of each radar as labelled on the diagram. The short-range part of the FoV $(180-765 \mathrm{~km})$ where the E-region backscatter is expected is shown in dark blue for each radar. Also shown are the positions of two ionosondes at Hobart and on Macquarie Island. The curved grey line is the line of constant magnetic latitude $\Lambda=60^{\circ} \mathrm{S}$. The lines of constant geometric aspect angle at $110 \mathrm{~km}, \alpha=-1^{\circ}, 0^{\circ}$ and $+1^{\circ}$, are shown by the red, orange and yellow circular lines, respectively. The green lines represent the model real aspect angle lines $\alpha_{R}=0^{\circ}$ at $110 \mathrm{~km}$ calculated using a peak electron density of $4 \times 10^{4} \mathrm{~cm}^{-3}$ (see text for details).

tron density/refraction becomes more significant, the lines of nearly perfect aspect angle will move closer to each radar as was demonstrated in Fig. 1, in which the green lines of real aspect angle (with refraction) were closer to the radar than the lines of geometric aspect angle (no refraction). Consequently, the echoes are expected to be observed closer to the radars with the electron density/refraction increasing.

\subsection{Echo occurrence characteristics}

The variation in echo occurrence with time was first investigated for both of the TIGER radars to determine the conditions favourable for irregularity generation and detection. For each month and for each 30-min time interval, the total number of echoes detected within the near FoV $(r \leq 585 \mathrm{~km})$ was calculated and summed over all days in a given month. The echoes were only counted if both radars were operational on that particular day. The echo counts were also normalized to 120 -s resolution mode, taking into account that a radar operating in a 60 -s mode would potentially detect twice as many echoes as when the radar operates in a 120 -s mode.

Figure 2 shows the variation of echo occurrence as a function of UT in January-June 2006. The blue (red) line represents the measurements made by the Bruny Island (Unwin) radar. The first feature worth noting here is the large difference in the total number of echoes detected between the two 


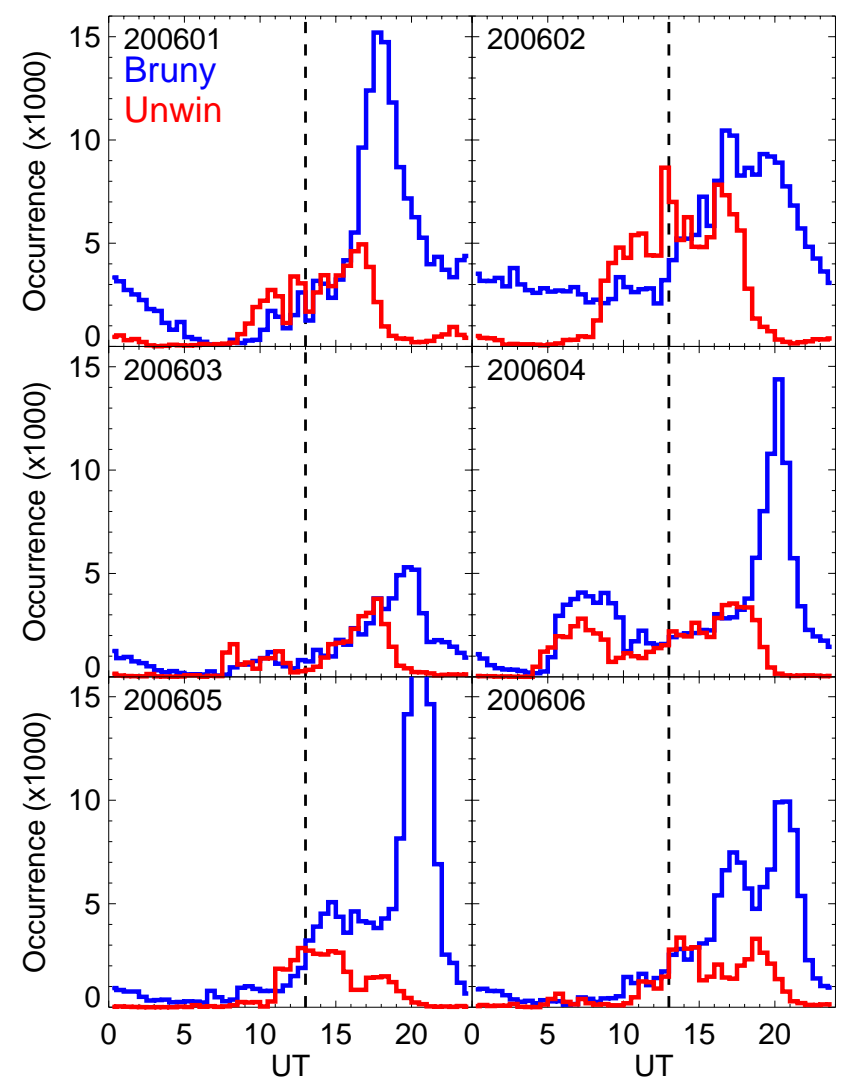

Fig. 2. The number of echoes detected by each TIGER radar as a function of Universal Time summed over all days for each month in the first half of 2006. The blue (red) curve corresponds to measurements made by the Bruny Island (Unwin) radar. Magnetic midnight $(\sim 13: 00$ UT) is indicated on each plot by the dashed vertical line.

radars. The Bruny Island radar observed far more echoes than Unwin consistently throughout the period of interest with the exception of the period 08:00-18:00 UT in JanuaryApril 2006, during which the occurrences were comparable. The majority of echoes were detected in the morning sector (16:00-22:00 UT). These features are also present throughout the entire dataset (November 2004-December 2006, not shown here). Of particular interest is the period of April 2006 when both echo number variations exhibit a secondary peak at 04:00-10:00 UT in the evening sector. In other months, the evening-time echo occurrence rates were small. The echo occurrence was however increasing towards the end of the interval 04:00-10:00 UT in January-February 2006.

It is clear from Fig. 2 that the total echo numbers detected by the two TIGER radars were quite different. This result is not surprising since the two radars have different backscatter conditions as was illustrated in Fig. 1. In particular, Unwin observes at smaller $L$-shell angles than the Bruny Island radar, and locations with minimum geometric aspect angles are also different, Fig. 1. Hence one expects the echo locations and spatial occurrence patterns to differ as well. The total number of echoes is determined by the summation over the area where the echoes are observed. Therefore, it is more meaningful to compare the maximum occurrence rates within the FoV rather than the total numbers of echoes.

For this comparison, the 1-h echo occurrence rates in percentage were determined for each radar $(\operatorname{rad}=b, u)$, each day with the simultaneous data for both radars in $2006(d=1-$ $279)$, each hourly interval $(h=0-23)$, each radar radar beam $(i=0-15)$, and each E-region range gate $(j=0-9$ or range $180-585 \mathrm{~km}):{ }^{\mathrm{rad}} n_{i j}^{d h}$. These were calculated by summing all echo counts (up to 60 at 1-min resolution) for a given radar cell and hourly interval and dividing by 60 (30) at 1-min (2$\mathrm{min})$ resolution. The maximum occurrence value within the near FoV was then selected for each 1-h interval and for each radar: ${ }^{\mathrm{rad}} N_{\max }^{d h} \equiv \max _{i j}\left({ }^{\mathrm{rad}} n_{i j}^{d h}\right), d=1-279, h=0-23$.

The data were then sorted and averaged according to the daily maximum $K_{p}$ index as follows. Out of 279 days in 2006, 164 days had daily maximum $K_{p}$ index in the range $0 \leq K_{p \max }<3$. This first group of days is denoted as $D_{1}$. Out of remaining $279-164=115$ days, 94 days were within $3 \leq K_{p \max }<5$, and 21 days had $5 \leq K_{p \max } \leq 9$. These two groups are denoted as $D_{2}$ and $D_{3}$, respectively. Averaging over all daily variations for each group separately was then employed: ${ }^{\mathrm{rad}} N_{\text {mean } \max }^{1 h} \equiv \frac{1}{164} \sum_{d \in D_{1}}^{\mathrm{rad}} N_{\text {max }}^{d h}$, ${ }^{\mathrm{rad}} N_{\text {mean max }}^{2 h} \equiv \frac{1}{94} \sum_{d \in D_{2}}^{\mathrm{rad}} N_{\text {max }}^{d h}$, and ${ }^{\mathrm{rad}} N_{\text {mean max }}^{3 h} \equiv \frac{1}{21} \sum_{d \in D_{3}}^{\mathrm{rad}} N_{\text {max }}^{d h}, \quad h=0-23 . \quad$ The resulting diurnal variations of the mean maximum occurrences for both TIGER radars $\left({ }^{b} N_{\text {mean max }}^{m h}\right.$ and ${ }^{u} N_{\text {mean max }}^{m h}, m=1-3$, $h=0-23)$ are compared in Fig. 3 for each group separately. The total number of days within each group $(m=1-3)$ is given in the top-right corner of the respective panel.

The overall shape of diurnal variations for the two radars is similar in both panels (a) and (b) with the Unwin peak occurrence observed earlier. In sharp contrast to Fig. 2, the average maximum occurrences have very similar values and diurnal variations for almost half of the day (04:00-15:00 UT). After 15:00 UT (02:00 MLT), the diurnal variations start to behave differently; the Unwin occurrence quickly decreases with time, while the Bruny radar detects increasingly frequent echoes. The occurrence rates also increase with geomagnetic activity level from $30 \%(20 \%)$ of peak occurrence for Bruny (Unwin) in (a) to 51\% (34\%) in (c). A small 1-2 h offset between the Unwin occurrence maxima as compared to those for Bruny in Fig. 3 may be caused by the longitudinal difference (equivalent to $\sim 1.5 \mathrm{~h}$ in MLT) between the radars' locations and near FoVs. However, even with this offset it is difficult to explain different behaviour of the radars' occurrences after 02:00 MLT. Perhaps this feature is related to significantly different propagation conditions for the two radars in this time sector. The rigorous ray-tracing modelling involving electron density measurements within the near FoVs of both radars (which are not available at present) would be required in order to explain this feature. 
One can conclude from the above analysis that even though the total numbers of echoes detected by the two TIGER radars differed significantly, the difference is less pronounced when the maximum occurrence rates are considered. In particular, the mean maximum occurrences are very similar in both the evening and post-midnight sectors.

\subsection{Spatial echo occurrence patterns}

We next examine the spatial distribution patterns of the HF echoes by considering range-versus-beam plots. Similar to Fig. 2, the dataset is again broken into monthly periods. All echoes detected in a month are now summed together for each beam and range bin. Figure 4 shows the spatial distribution of the echoes detected by the Unwin radar in JanuaryApril 2006 in the (a) morning (16:00-22:00 UT) and (b) evening sectors (04:00-10:00 UT). The contours represent the normalized occurrences expressed as a percentage of the maximum value in each plot (e.g. the $90 \%$ contours enclose red areas with radar cells exceeding $90 \%$ of maximum occurrence including cell(s) with maximum occurrence of $100 \%$ ). These maximum values are shown in each plot together with the total number of echoes.

Some strong differences are evident between the morning and evening sectors from Fig. 4. The data from the morning sector (a) display a band of echoes detected across all beams at ranges $180-405 \mathrm{~km}$ for all 4 months. The evening sector data (b) show significant variations in the echo distribution pattern from month to month. A notable feature in (b) is a substantial number of echoes being detected at ranges $>585 \mathrm{~km}$ consistently throughout January-April. These echoes most likely originate from the F-region and thus will not be included in the statistical analysis of E-region backscatter hereinafter. A band of the E-region echoes similar to that shown in panel (a) is evident in January. However, it is not as obvious for the other months, most likely due to the F-region backscatter dominating the occurrence pattern. Interestingly, a "curved" band of echoes stretching from the maximum plotted ranges in beam 6 to ranges of $450 \mathrm{~km}$ in beam 15 is obvious in April 2006. Nothing reminiscent of this feature is present in the morning sector plots. The relative occurrence is quite substantial even if compared with that in the $\mathrm{F}$ region (60\% versus $100 \%$ of maximum). In absolute terms, up to 243 echoes ( $60 \%$ of the maximum of 405 ) were observed within the cells of the curved band, which is larger than in any other month in the evening sector (e.g. $20 \%$ of 564 or $\sim 110$ in February).

The same analysis was performed for all other monthly intervals within the dataset showing very similar characteristics to those displayed in Fig. 4. In some months the curved band feature seen in Fig. 4 made other appearances in the evening sector with a similar feature being also observed by the Bruny Island radar in the same months. The feature identified in the Bruny Island radar data has a similar curvature as the feature in the Unwin data, only with an opposite sense

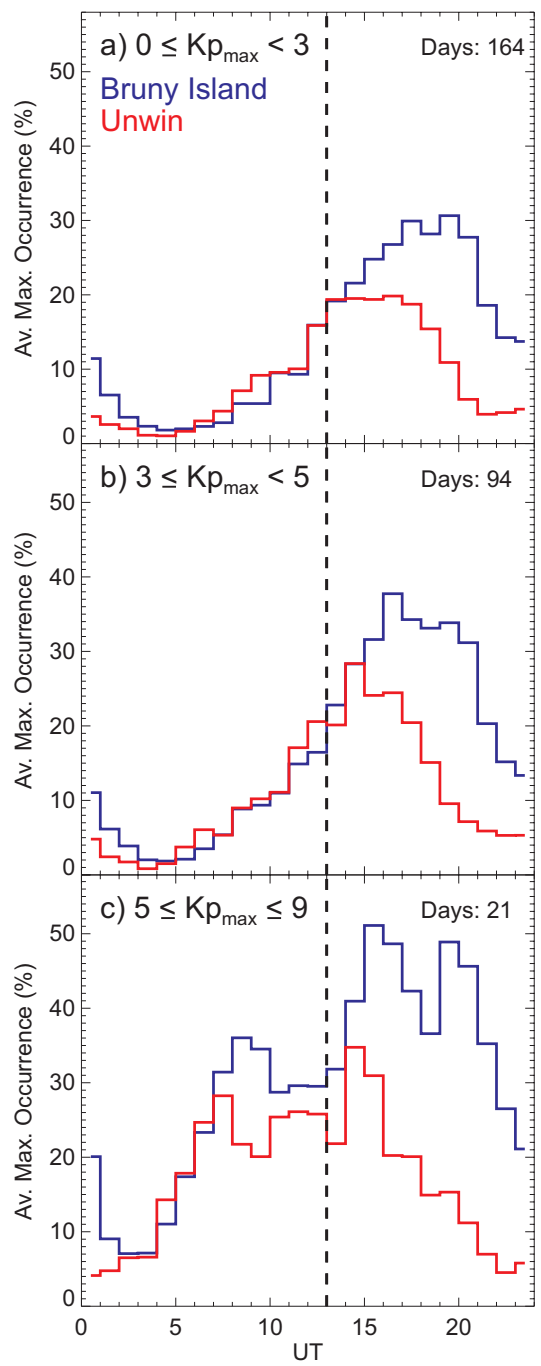

Fig. 3. The mean maximum occurrence over all days with the maximum $K_{p}$ (a) $0 \leq K_{p \max }<3$, (b) $3 \leq K_{p \max }<5$ and (c) $5 \leq K_{p \max } \leq 9$ throughout 2006. The blue (red) curve represents data measured by the Bruny Island (Unwin) radar. The number of days considered within each plot is shown in the top-right corner. Magnetic midnight $(\sim 13: 00$ UT) is indicated on each plot by the dashed vertical line.

of curvature. That is, for small beam numbers the band is centered at ranges $300-500 \mathrm{~km}$ extending to the maximum plotted ranges in beam 15. The months when these features were observed by both TIGER radars were November 2004, January 2005, May 2005, September 2005, April 2006, and December 2006. During each of these months, one or more periods of increased geomagnetic storm activity as indicated by the $K_{p}$ and $D_{s t}$ indices were observed. Hence the spatial occurrence patterns for periods of increased storm activity ( $K_{p} \geq 5$ and $D_{s t} \leq-50 \mathrm{nT}$ ) were examined to determine if the curved band was a storm-related feature.

Figure 5 is the same as Fig. 4 but with the data restricted to specific storm days (indicated at the top of each column) 


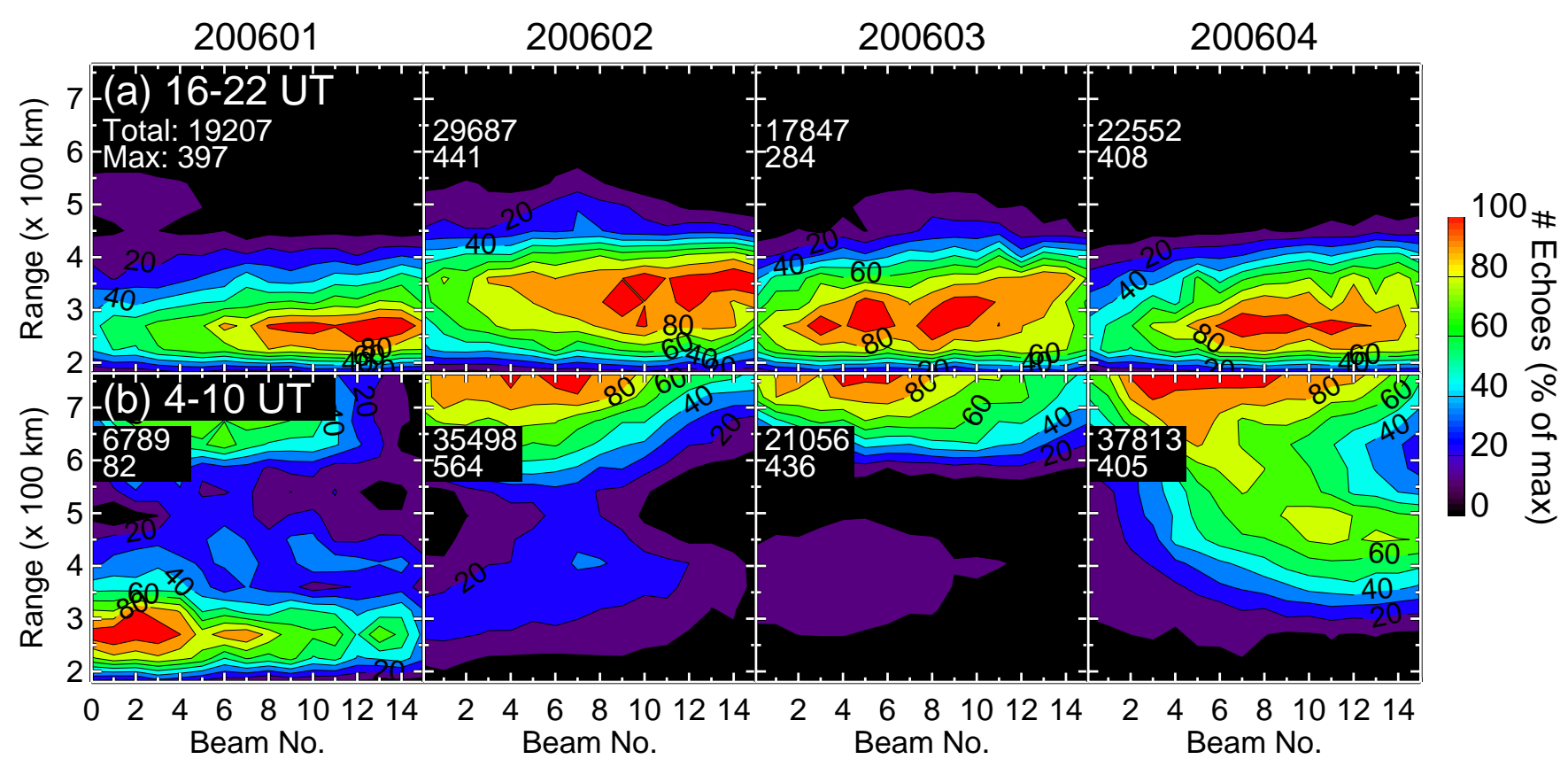

Fig. 4. Normalised spatial distribution of short-range echoes as observed by the Unwin radar. Panel (a) shows the spatial distribution for the morning sector (16:00-22:00 UT) in January-April 2006. Panel (b) is the same as panel (a), but for the evening sector (04:00-10:00 UT). The total number of points included in each plot is indicated in the top-left corner along with the maximum value of occurrence. The colour scale is shown on the right.

as observed by the (a) Unwin and (b) Bruny radars. The curved feature is present in all of the examples of stormtime data that are shown in the diagram. The rightmost column of panel (a) displays the data that formed the curved feature in Fig. 4. Here it is much more prominent due to only storm-time data being considered in this plot. It can be seen that the ranges at which the feature is observed by Unwin differ somewhat from storm to storm, e.g. the band is centered at $495 \mathrm{~km}$ in beam 2 for 9 November 2004 as compared to $540 \mathrm{~km}$ for 18 January 2005 . The sense of curvature of the feature, on the other hand, is identical for each case. Similar characteristics are also observed in the Bruny Island data plots, also with some small variations in range. Other differences between the plots include both the total number of counts and the maximum number of echoes. Despite the large differences in these values, the curved feature is quite prominent for all storm events.

Importantly, we notice that the sense of curvature exhibited by the storm-time feature is similar to that of the geometrical aspect angle lines in Fig. 1 for both radars. Thus the feature was the closest to the radar in beam 15 (0) for the Unwin (Bruny) radar and this is exactly what is seen in Fig. 1 in the near FoV. These geometrical aspect angle lines are also plotted in Fig. 5 to examine the storm-time feature in relation to the expected location of backscatter. Figure 5 certainly shows a strong similarity between the curvature of the feature and that of the aspect angle lines. The curved feature is present for both radars and for all 4 storm events. One can conclude that the E-region backscatter at HF in the evening sector is observed in locations with small geometric aspect angles during high geomagnetic activity.

\subsection{Echo type analysis}

Having examined the echo occurrence characteristics of all E-region echoes detected by the TIGER radars, the types of echoes making up the dataset in the evening sector are now investigated by analyzing their measured spectral parameters. In the past, the grouping of echo types according to their spectral characteristics has been a useful tool in identifying the generation mechanisms of the irregularities observed by various radars (e.g. Watermann et al., 1989; Hanuise et al., 1991; Milan and Lester, 2001; Makarevitch et al., 2001).

The populations of echoes detected between 04:0010:00 UT over a 4-month period are investigated by plotting spectral width versus Doppler velocity in Fig. 6 for the (a) Unwin and (c) Bruny radars. Similarly, the Doppler velocity versus $\mathrm{L}$-shell angle is plotted in Fig. $6 \mathrm{~b}$ and d. The 2-D occurrence plots were produced with bin widths of $20 \mathrm{~m} / \mathrm{s}$ for the Doppler velocity and $25 \mathrm{~m} / \mathrm{s}$ for the spectral width in Fig. $6 \mathrm{a}$ and c. In Fig. $6 \mathrm{~b}$ and $d$ they were $3^{\circ}$ for $\mathrm{L}$-shell angle and $40 \mathrm{~m} / \mathrm{s}$ for the Doppler velocity. The number of echoes within each plot cell were counted throughout the period of interest, January-April 2006, for ranges $\leq 585 \mathrm{~km}$. The values shown are normalised to the maximum value in the plot shown by the digits (together with the total number of echoes 


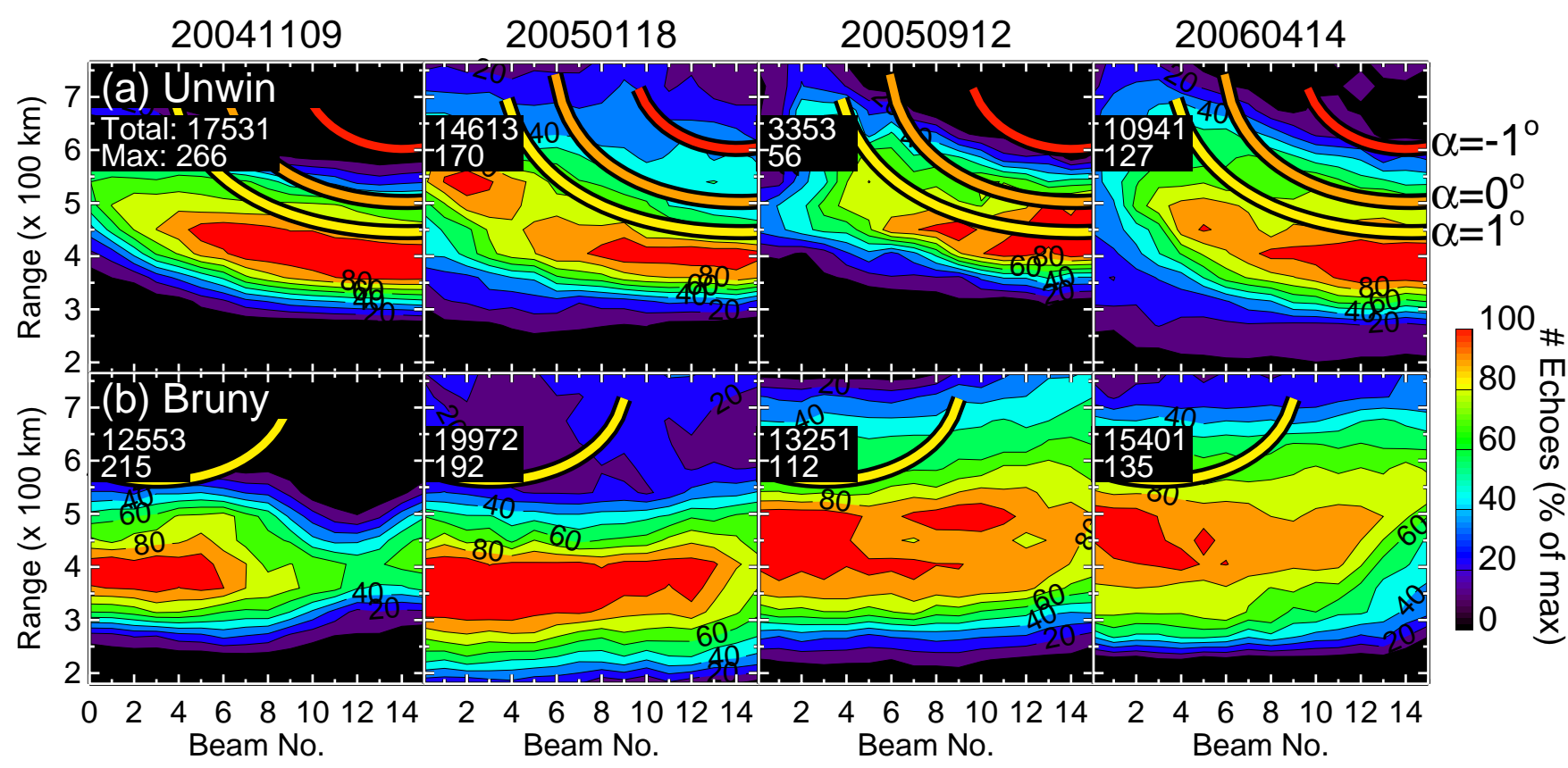

Fig. 5. Same as Fig. 4, but for the (a) Unwin and (b) Bruny Island data restricted to specific storm events in the evening sector. The date for each event is indicated at the top of each column. Constant geometrical aspect angle lines $\alpha=-1^{\circ}, 0^{\circ}$, and $+1^{\circ}$ are also shown.

in Fig. 6a and c), expressed as percentage. Only the plot cells with significant number of points within a given cell are shown: above 50 points in panels (a) and (c) and above 30 in (b) and (d). The colour scheme is given in Fig. 6a.

Figure 6a and $\mathrm{c}$ show that there is a considerable difference in the total numbers of echoes detected by the two radars (44689 for Unwin versus 72730 for Bruny). The value for the maximum occurrence, on the other hand, is substantially larger in the Unwin dataset (7474 vs. 2239). The plots show the existence of two populations within the datasets of both radars. The first population has an inverted funnel-like shape in width-velocity plots, i.e. the range of velocities increases slightly as width decreases. These echoes have low Doppler velocities near $0 \mathrm{~m} / \mathrm{s}$ and are hereinafter referred to as the low-velocity echoes. This population is more obvious for the Bruny Island radar as the widths measured by Bruny are in the range $0-500 \mathrm{~m} / \mathrm{s}$, while Unwin generally measured smaller widths $(0-200 \mathrm{~m} / \mathrm{s})$. Most Unwin echoes have low widths and small negative velocities ( 3 red cells near the origin). The second population overlaps the first population and has a "flare"-like shape in width-velocity plots, i.e. width tends to increase as velocity becomes more negative. These echoes have spectral widths between $100-300 \mathrm{~m} / \mathrm{s}$ and small negative velocities of $0-200 \mathrm{~m} / \mathrm{s}$. This population seems to be centered at $V \cong-100 \mathrm{~m} / \mathrm{s}$ and $W \cong 125 \mathrm{~m} / \mathrm{s}$ in panel (c). In Fig. $6 \mathrm{~b}$ and $\mathrm{d}$ we investigate the variation of Doppler velocity with L-shell angle for the same data as in Fig. 6a and c, respectively. Again, it is obvious that the low-velocity population with velocities $\simeq 0 \mathrm{~m} / \mathrm{s}$ dominates the datasets of both radars. The velocities tend to become more negative with $L$ shell angle increasing in Fig. 6d. The second population is not seen clearly in both Fig. $6 \mathrm{~b}$ and d.

The analysis above was performed for the evening sector during a 4-month period. Our dataset is therefore made up of the data collected predominantly during geomagnetically quiet conditions. It was found in Sect. 2.2, however, that a geomagnetic storm took place on 14 April 2006, which was included within the data that was analysed above. This prompts us to investigate any storm-time dependence of the spectral characteristics exhibited by the two echo populations identified above. This examination is conducted using the $D_{s t}$ index as described below.

Figure $7 \mathrm{a}$ and $\mathrm{c}$ show the same data used to construct Fig. 6a and c, respectively, only with each data point colourcoded in $D_{s t}$. One can easily identify the two populations within both plots, but it is the second population that stands out the most, with all points corresponding to highly negative $D_{s t}$ values of magnitude 50-80 nT. This storm-time population is observed by both radars, again despite their largely different viewing geometries. It is also interesting to note that the low-velocity population contains measurements that were predominantly obtained during periods of relatively low geomagnetic activity $\left(D_{s t}>-40 \mathrm{nT}\right)$ with the exception of low-velocity echoes near zero observed by Unwin that have $D_{s t} \sim-90 \mathrm{nT}$. Finally, one should note that a similar analysis was performed using the $K_{p}$ index rather than the $D_{s t}$ index with results being very similar. 

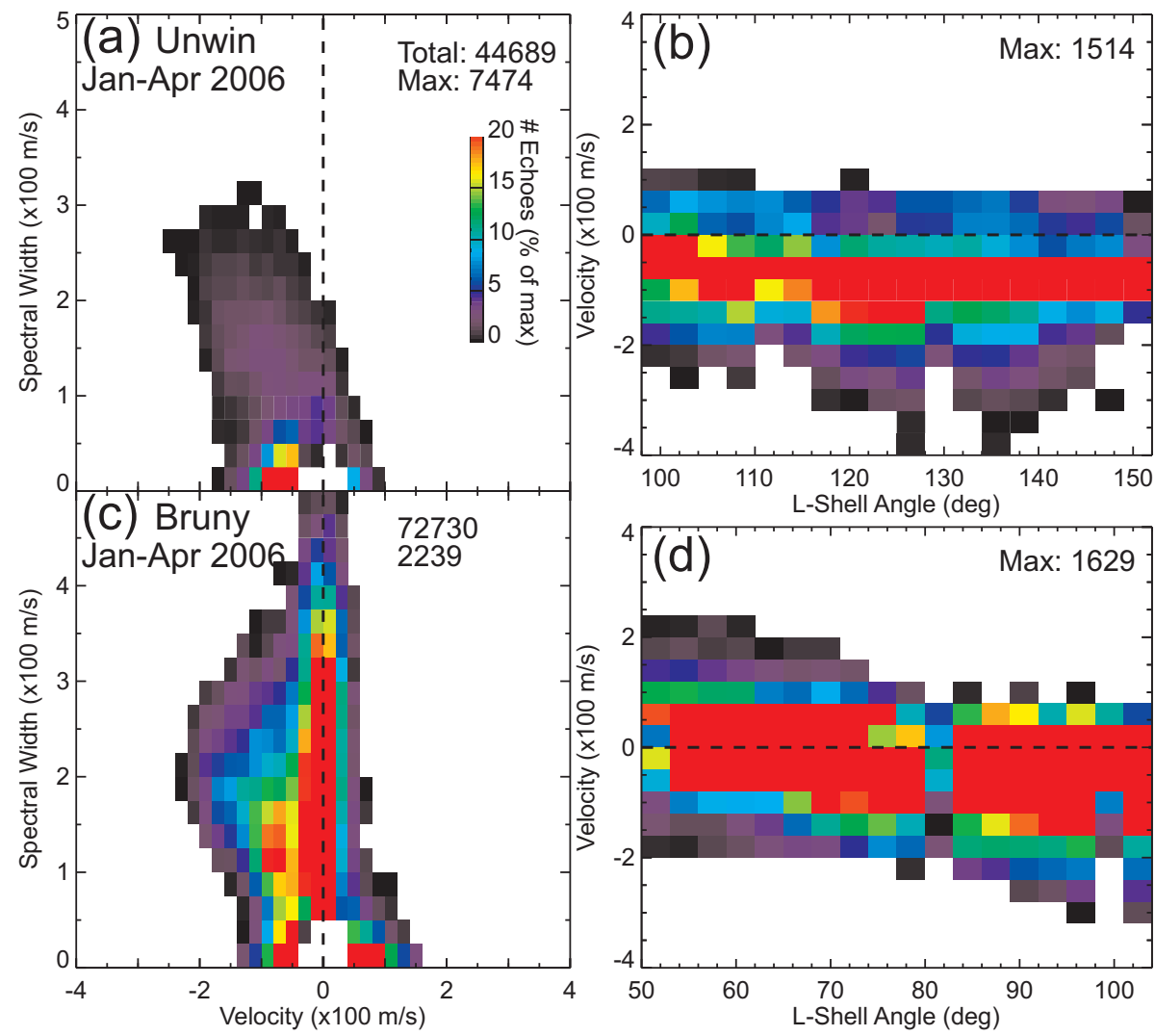

Fig. 6. Panels (a) and (c) show the 2-D occurrence plots of the spectral width versus Doppler velocity for the Unwin and Bruny Island radar, respectively. The data were collected in the evening sector in January-April 2006. The values shown are the numbers of echoes divided by the maximum echo number in all plot cells and expressed as percentage. The colour scale is indicated in panel (a). The total number of echoes and the maximum echo number are indicated in the top-right corner of each panel. Panels (b) and (d) show similar 2-D occurrence plots of the Doppler velocity versus L-shell angle.

Figure $7 \mathrm{~b}$ and $\mathrm{d}$ are similar plots to Fig. $7 \mathrm{a}$ and $\mathrm{c}$, but now only considering the storm-time data taken from the evening sector (04:00-10:00 UT) during the 14 April 2006 storm, with each data point colour-coded in slant range as indicated. The range of Doppler velocities plotted has been reduced to $[-300,+100] \mathrm{m} / \mathrm{s}$ to focus on "flare"-like population. The maximum plotted slant range was increased from $585 \mathrm{~km}$ to $765 \mathrm{~km}$ to determine whether it is possible that this population is linked in any way to the F-region backscatter. Now that each data point is colour-coded in range, any F-region backscatter significantly contributing to the population would be easily recognised.

Analyzing the storm-time population in further detail reveals significant differences between what were first thought to be two very similar populations observed by the Unwin and Bruny Island radars. The Unwin radar population in Fig. $7 \mathrm{~b}$ spreads across the plotted area with range increasing as the Doppler velocity becomes more negative. A similar population exists in Fig. 7d for the Bruny Island radar along with an additional cluster of echoes at short ranges $(\sim 300 \mathrm{~km})$ exhibiting negative Doppler velocities of magni- tude $140-200 \mathrm{~m} / \mathrm{s}$ (blue points). The latter population is of particular interest due to its approximately constant velocity and range, and it will be examined further in Sect. 3.4. Finally, no evidence of significant contribution from the Fregion backscatter to the storm-time population is present in Fig. 7, as most of the storm-time echoes are observed at $r \leq 585 \mathrm{~km}$.

\section{Discussion}

In this study, we analysed short-range E-region backscatter detected at magnetic latitudes $58^{\circ}-60^{\circ} \mathrm{S}$ by the two TIGER HF radars. An approximate 2-year period was considered when both radars were in operation, late 2004-2006. Analysis of the diurnal variation of the echo occurrence, Fig. 2, showed that the majority of short-range echoes $(r<585 \mathrm{~km})$ were detected in the morning sector, which is consistent with the results found from previous auroral HF radar studies (Hanuise et al., 1991; Makarevitch et al., 2002a). The higher occurrence in the morning sector is interpreted as being due to the larger overlap of the radar FoV with the auroral oval in 


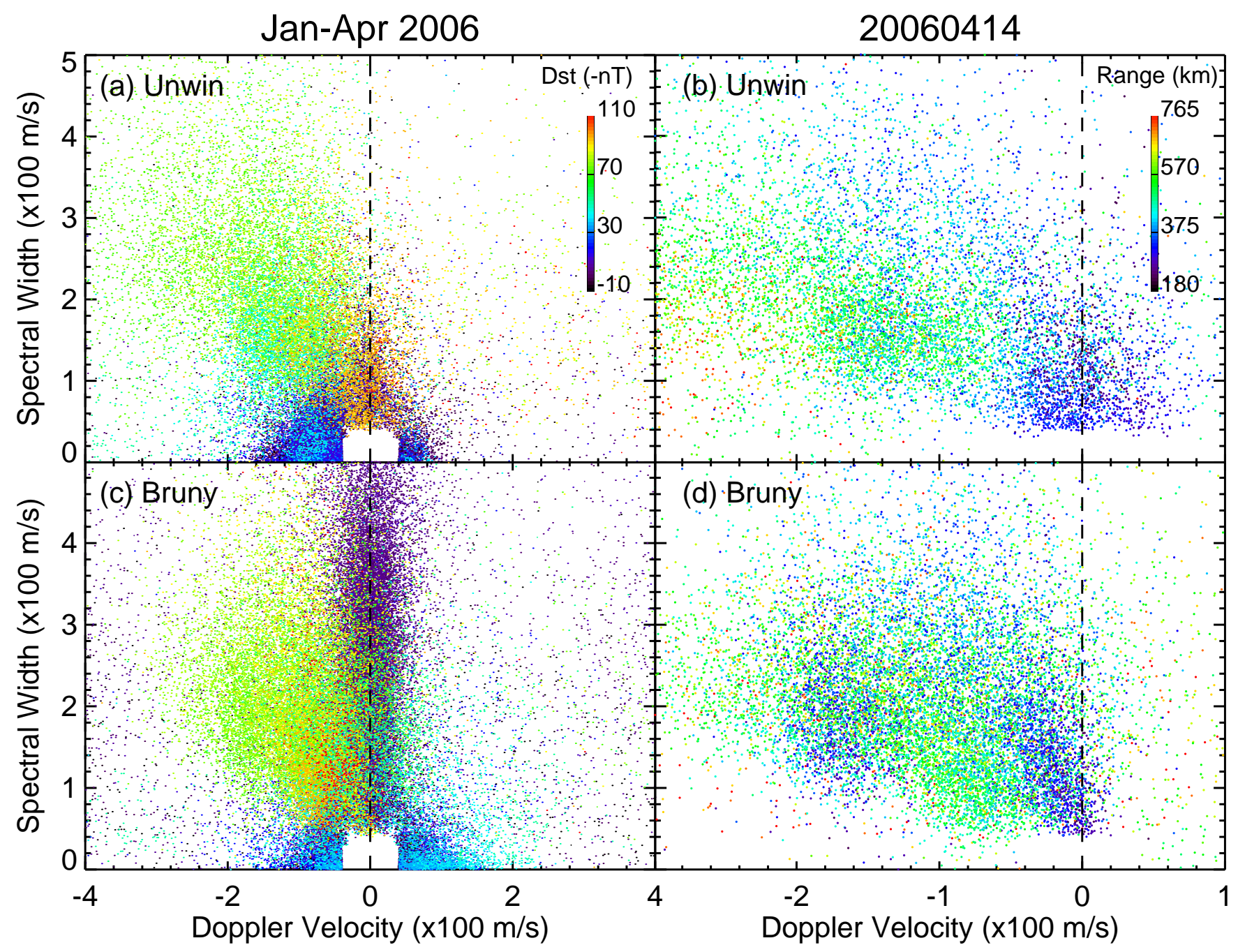

Fig. 7. Spectral width versus Doppler velocity scatter plots for the (a) Unwin and (c) Bruny Island radar data. The data were collected in the evening sector in January-April 2006 and colour-coded in $D_{s t}$ index as indicated in panel (a). Panels (b) and (d) show the data collected with the Unwin and Bruny Island radar, respectively, during the 14 April 2006 storm event. The points are colour-coded in slant range as indicated in panel (b).

the local morning hours (e.g. Hanuise et al., 1991). It should be noted however, that our database was significantly larger than in the previous studies. This study also considered the data from both the morning and evening time sectors due to the large number of data points available in both of them, with particular focus on the evening sector observations.

In this section, we first discuss diurnal variations and echo occurrences as observed by the two TIGER radars, Sect. 3.1. The results on the spatial echo occurrence patterns during storms are interpreted and discussed in Sect. 3.2 in the context of variations in the E-region electron density. The discussion of various echo populations observed by the two TIGER radars is presented in Sect. 3.3 with particular focus on the storm-time population, Sect. 3.4.

\subsection{Echo occurrences for the Bruny and Unwin radars}

Overall, the Bruny Island radar observed more echoes than the Unwin radar, Fig. 2. However, the difference was most pronounced in the late-morning and afternoon sectors (15:00-20:00 UT), whereas in the evening sector the occurrences were often comparable. In Fig. 6a and c, the Bruny Island radar observed $\sim 60 \%$ more echoes in total. The radars observed the echoes at different ranges and different angles with respect to the flow, that is the number of radar cells which contributed to the the total echo count were different for the two radars. This is clearly illustrated by much larger areas enclosed by all contours in Fig. 5 corresponding to the 12 September 2005 storm event. Importantly, the occurrence maxima were also different (by a factor of $2 ; 56$ vs. 112) even though the mode (and hence time resolution) was the 
same. However, the difference between the total numbers was even greater (a factor of $\sim 4$ ), which demonstrates that it is more meaningful to compare the maximum occurrences rather than total numbers. It was found that the average maximum occurrences were close and behaving in a similar fashion throughout the period of interest, Fig. 3.

It was also noticed that in Fig. 6a and c there were more echoes per plot cell (near the maximum occurrence; red colour) as observed by the Unwin radar when compared to the Bruny Island radar (7474 versus 2239). This may indicate that Unwin saw more echoes of a certain type (near a given velocity and width) while other types were not observed. However, the examination of the echo types did not indicate that this was the case. To the contrary, the measurements made by the Unwin radar exhibited very similar characteristics to those by the Bruny Island radar with both populations of echoes present in both datasets. The population that contributed to the total number of echoes the most was the low-velocity population and it was well-pronounced in both radar datasets.

The similarity between echo populations observed by the two TIGER radars as well as that between maximum occurrence values suggests that the difference in the total number of echoes detected by the two TIGER radars is, in part, due to different backscatter conditions and, in part, due to a difference in the radars' receiving sensitivity and/or transmitting power.

\subsection{Spatial distribution of storm-time echoes}

An interesting new feature found was the curved band of echoes appearing in the range-beam occurrence plots at various times as observed by the TIGER radars. It was found that these times were coincident with geomagnetic storms. No such association between the short-range E-region HF echoes and storm-time conditions was reported before, while it may prove to be an important aspect of (and a useful tool for monitoring) the plasma dynamics during storms.

The band of storm-time echoes was detected very close to the locations with small geometric aspect angles, Fig. 5. One expects that the real aspect angles (with refraction) will be different from the geometric ones, with the small real aspect angles occurring at closer ranges, Fig. 1. In our observations during storms in the evening sector, the E-region echo band was found to occur at locations nearly coincident with the geometric aspect angle lines, a result expected for observations at VHF and UHF (no refraction) but not at HF. This result implies that the electron density must have been relatively small during these times so that no significant refraction occurred.

To provide additional evidence in support of this interpretation, the data collected by the ionosondes at Hobart and Macquarie Island were employed. Although these ionosondes are not located within the near FoV of either of the TIGER radars, Fig. 1, the information on the electron density at the times where the curved band was present may still be useful, in particular in terms of its time variation. Better insight could be obtained if ionosondes were located in the region where the radar rays propagate, but, unfortunately, no such data were available in the present study.

Figure 8 shows three storm-time examples when the Eregion backscatter was present in the TIGER data and when there was sufficient data from at least one of the nearby ionosondes. The three rows (a), (b) and (c) display data collected during the 17 January 2005, 18 January 2005 and 14 April 2006 storm events, respectively. The three columns correspond to the data collected by the Hobart ionosonde and by the Bruny Island and Unwin radars, respectively. Unfortunately, the Macquarie Island ionosonde recorded very few measurements during these intervals. The first column shows the storm-time hourly median critical frequencies $f_{0} E$ (black circles), quiet day variations (diamonds), and relative change from the quiet day level $\Delta f_{0} E$ (blue circles) with the scale shown on the right. The second and third columns are the range-beam occurrence plots in the same format as Fig. 5. The TIGER radar data were again considered for the evening sector observations 04:00-10:00 UT; these times are indicated by the dashed lines in the first column. The quiet day variation for a given month was obtained from taking the median of the hourly median $f_{0} E$ values over the 5 quietest days, i.e. those that exhibited minimum magnitude of the $D_{s t}$ index.

In all 3 storm events, the critical frequency of the E layer was decreasing throughout the time interval of interest. However, only panels (b) and (c) show a well-defined curved echo band, whereas panel (a) shows a nearly flat echo band for both the Bruny Island and Unwin radars. The ionosonde data presented in panels (b) and (c) show a steeper gradient than in panel (a), as well as smaller minimum values: $2.25 \mathrm{MHz}$ for (a) versus $1.9 \mathrm{MHz}$ and $1.8 \mathrm{MHz}$ for (b) and (c), respectively. This is also reflected in the relative variations (from quiet level) that are much larger in panel (a) as compared to panel (b). In panel (c), the relative variations are negative throughout the event. The progressively lower $f_{0} E$ values from panel (a) to (c) support the idea that the curved bands are observed when a reduction in the electron density occurs. The magnitude of this reduction may depend on the time of the day, season, and storm time as discussed below.

Even though the first two events are from the same storm, the curved feature only occurs on the second day. This suggests that a reduction in the E-region electron density occurs later in the storm development cycle. The E-region density is mostly controlled by seasonal and diurnal variations with large densities during the daytime which decay rapidly after sunset. The nighttime electron densities, on the other hand, are significantly affected by short-lived precipitation events. It is perhaps because of this large variability that the storm-time plasma dynamics in the $\mathrm{E}$ region has not received much attention in the past. However, our results are consistent with the previous studies on the E-region density variations during storms on a longer time scale. Thus the median 


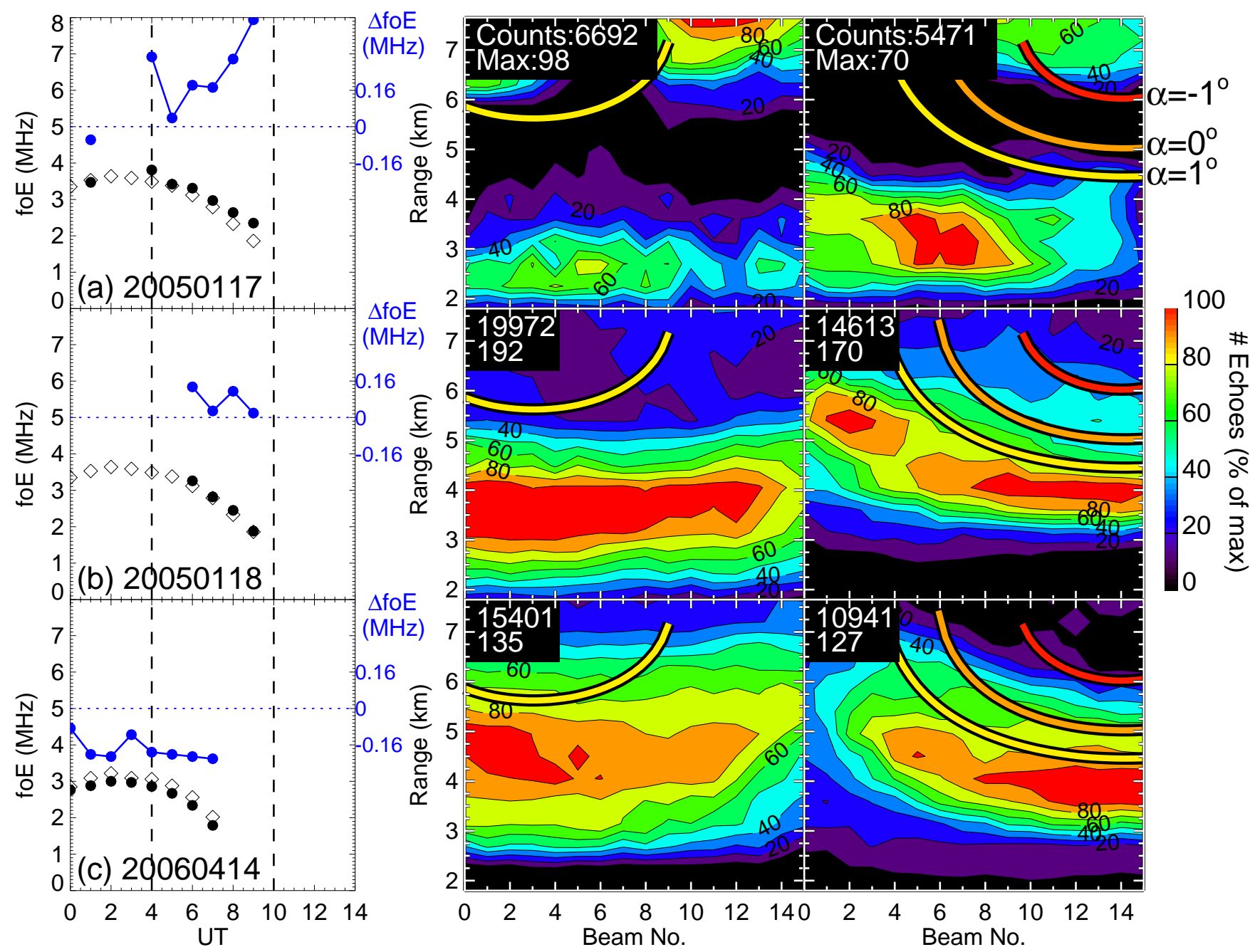

Fig. 8. Examples of the Hobart ionosonde measurements (left column) and spatial occurrence plots for the Bruny Island (center column) and the Unwin (right column) radars for the three selected storm events: (a) 17 January 2005, (b) 18 January 2005 , and (c) 14 April 2006. The variation of the storm-time hourly median $E$ layer critical frequency $f_{0} E$ (black circles) is shown along with the quiet time variation (diamonds). The difference between the measured storm-time critical frequency and that measured during quiet time $\left(\Delta f_{0} E\right)$ is also plotted as blue circles. The scale for $\Delta f_{0} E$ is shown on the right. The interval of interest 04:00-10:00 UT is shown by the dashed lines. The plots in the center and right columns are in the same format as Fig. 5.

hourly $f_{0} E$ values in mid-latitudes have also been shown to exhibit some electron depletion well after storm commencement (SC) (Brown and Wynne, 1977; Kane, 1979).

Figure 8 shows that an electron depletion was not present during the first day 17 January 2005, while on the next day the $\Delta f_{0} E$ value was still positive but much smaller. Both the $f_{0} E$ values and relative variations $\Delta f_{0} E$ were lower on 14 April 2006. The ionosonde observations thus support the idea that reduced electron densities were, in part, due to the electron depletion during storms.

This result disagrees somewhat with that reported by Ogawa et al. (2002) who demonstrated the shortening of ranges where the storm-time E-region backscatter was observed, which implies a density enhancement during storms.
One could explain this apparent discrepancy by arguing that the curved band reported here is only present well after SC, whereas Ogawa et al. (2002) have concentrated on observations taken during the initial storm phase. During this phase the densities are either comparable to or higher than the quiet day values, while maximum depletion is observed $\sim 20 \mathrm{~h}$ after SC (Brown and Wynne, 1977). On the other hand, the disagreement may be due to large variability on a shorter time scale as well as from one storm event to another.

Finally, one can hypothesize that the difference between statistical spatial occurrence patterns in the morning and evening sectors, Fig. 4, was also due to a larger, on average, electron density in the morning sector. Unfortunately, low statistics of ionosonde data in the morning sector did 
not allow us to compare the $f_{0} E$ variations directly. However, analysis of storm-time morning echo occurrence plots similar to Fig. 5 (not presented) revealed that the curved feature was present only in one of the storm events shown in Fig. 5 (9 November 2004). Moreover, the echo occurrence was often low during storms in the morning sector, in particular as seen by Unwin. It is therefore possible that the absence of the curved feature in Fig. 4 in the morning sector was not caused by the larger density in the morning sector during storms, but simply occurred because there was little backscatter during morning storm-time periods when the density could have been as low as in the evening sector. If so, even though the density was low, the curved feature did not occur in the morning simply because there were no echoes to form it, and hence to contribute to the curved feature in the average monthly plots of Fig. 4. This is in contrast to evening sector observations during storms which provided the bulk of backscatter in monthly plots. This is supported by the data presented in Fig. 3 which shows that the evening time occurrence (04:00-10:00 UT) during strongly disturbed conditions, panel (c), was much larger than that under moderately disturbed and quiet conditions, panels (a) and (b), and that this difference was much smaller in the morning sector (16:00-22:00 UT).

\subsection{HF echo types}

The standard VHF echo type classification has been employed in numerous past studies, whereas the HF echoes have been shown to exhibit significantly different properties including different populations of echoes (Milan and Lester, 2001; Makarevitch et al., 2002a). Theoretically, Drexler et al. (2002) demonstrated that decameter-scale waves are completely dominated by convective processes. As a result, if the electric field is small, then so is the instability growth rate, which results in the irregularities propagating with the background velocity of electrons. For a large electric field (growth rate), the wave structures will be propagating at close to the ion-acoustic speed $C_{S}$.

In our observations, very few echoes had velocities above $250 \mathrm{~m} / \mathrm{s}$. The echoes from the dominant low-velocity population were observed at all $L$-shell angles with no obvious variation in occurrence with $L$-shell angle, Fig. $6 \mathrm{~b}$ and d. Their spectral widths were in the $0-500 \mathrm{~m} / \mathrm{s}$ range for the Bruny Island radar, while Unwin typically measured lower widths 0 $200 \mathrm{~m} / \mathrm{s}$, Fig. 6a and c. In the past, low-velocity VHF echoes with relatively large widths of the order of nominal $C_{s}(300-$ $400 \mathrm{~m} / \mathrm{s}$ ) have been classified as Type II echoes.

The dominance of the low-velocity population is an opposite result to that obtained by Schlegel et al. (1986) and by Meyer et al. (2004). Both studies considered VHF echoes at sub-auroral latitudes and showed that Type I echoes near the ion-acoustic speed $C_{S}$ were essentially the only population within their datasets. On the other hand, Type I auroral echoes have made significant appearances in other HF datasets (Hanuise et al., 1991; Eglitis et al., 1995; Haldoupis et al., 1996; Milan and Lester, 2001; Makarevitch et al., 2002a). It is hence unlikely that the lack of high-velocity echoes as compared to the previous studies is entirely due to the difference in scale size. It is not entirely clear why exactly high-velocity echoes were not present in the current study as strongly as in other datasets (auroral or sub-auroral).

An important feature of the low-velocity population is that it was dominated by narrow echoes with widths well below $C_{s}$. A large proportion of the low-velocity echoes observed by Bruny Island had relatively large widths (up to $500 \mathrm{~m} / \mathrm{s}$ ), but no clustering of points occurred near $300 \mathrm{~m} / \mathrm{s}$. Instead, the occurrence of low-velocity echoes with progressively larger widths was steadily decreasing, Fig. 6c. The large spectral widths of Type II echoes observed at VHF were attributed in the past to the strong coupling between linearly growing modes (Hamza and St.-Maurice, 1993). The large widths $(>300 \mathrm{~m} / \mathrm{s})$ observed by the Bruny Island radar for a substantial fraction of the low-velocity echoes had no counterparts in the Unwin data. One can suggest that this may be an instrumental effect, however, the fact that most of these echoes formed an integral part of the E-region band satisfying our data selection criteria does not support this. Irrespective of that, the majority of low-velocity echoes had low widths, which suggests that strong mode coupling processes are unlikely to be responsible for formation of the decameterscale low-velocity echoes.

Another feature that is difficult to explain invoking an analogy with Type II VHF echoes is the fact that the Doppler velocity of the low-velocity population rarely exceeded 100$150 \mathrm{~m} / \mathrm{s}$. Similar observations of unusually small velocities for a particular class of HF echoes observed at all $L$-shell angles were reported earlier by Makarevitch et al. $(2002 b$,a) and by Milan et al. (2003). This is in sharp contrast with the situation at VHF where the Doppler velocity steadily increases with the flow angle approaching zero. The VHF velocities regularly reach and even slightly exceed the $C_{S}$ for directions parallel to the plasma flow (e.g. Nielsen et al., 2002). One can conclude from the above that the low-velocity HF echoes observed in this study were significantly different from their VHF counterparts (Type II).

\subsection{Storm-time HF echoes}

A surprising new result of this study was the identification of the new storm-time echo population that was clearly associated with highly negative $D_{s t}$ index values, Fig. 7a and c. This population was less evident in Fig. $6 \mathrm{c}$ as it was "merged" smoothly with the low-velocity echo population, although a small local maximum in 2-D occurrence was evident at $V \cong-100 \mathrm{~m} / \mathrm{s}$ and $W \cong 125 \mathrm{~m} / \mathrm{s}$. Analysis of the scatter plots for individual days (not displayed here) showed that the echoes detected during periods of highly negative $D_{s t}$ in Fig. 7 were predominantly observed during the 14 April 2006 storm event. The echoes were observed by both 
TIGER radars and the spectral width of these echoes was increasing with the Doppler velocity so that this population was "branching-out" of the main low-velocity echo population in Fig. 7 at velocities $\simeq-100 \mathrm{~m} / \mathrm{s}$. To the best of our knowledge, no such storm-time population has been identified in the past either at HF, VHF or UHF. The echo characteristics appear to be similar to low-velocity echoes, e.g. velocity was varying in a similar fashion with L-shell angle so that no separate population was seen in Fig. $6 \mathrm{~b}$ and d. It is hence possible that somewhat elevated Doppler velocities of storm-time echoes were simply due to the enhanced electric fields during storm intervals. Analysis of the F-region velocities measured by the Bruny Island radar presented below supports this notion.

An intriguing feature observed for the storm-time echo population was that the spectral width was increasing as the Doppler velocity was getting more negative. Theoretically, the spectral width of Type II echoes is expected to be proportional to the drift velocity $V_{d}$ to the power of $4 / 3$ (e.g. Farley, 1985). The measured Doppler velocity itself is believed to be proportional to the drift velocity. Thus one expects $W \propto V_{d}^{4 / 3}$ relationship, which could explain the observed $W-V$ dependence in Fig. 6. On the other hand, one can speculate that this dependence may be a result of the FITACF algorithm not working properly. However, we have examined all ACFs for a 2-h period that included the interval during which the storm-time population was observed at 4 selected ranges and found little evidence of that. For an ACF to be considered "good" it had to show a steady linear decrease of phase with lag number and a steady decrease of the ACF amplitude (Ponomarenko and Waters, 2006). The percentages of "good" ACFs were approximately 91\%, 95\%, 86\%, and $99 \%$ for ranges $270,360,405$, and $450 \mathrm{~km}$, respectively. This analysis suggests that the relationship between width and velocity is unlikely to be an artefact of the FITACF algorithm. It is not entirely clear though why this dependence is seen for storm-time echoes but not for regular low-velocity echoes.

A closer examination of the storm-time echoes seen by the Bruny Island radar, Fig. 7d, showed that this population contained a separate cluster of echoes at small ranges near $360 \mathrm{~km}$ and at small negative velocities within the narrow range of $150-200 \mathrm{~m} / \mathrm{s}$. A similar result was obtained for the 15 December 2006 storm event as well (not presented here). Interestingly, this result is reminiscent of that obtained by Milan and Lester (2001) and by Milan et al. (2004) using the Pykkvibear HF radar. These authors found a separate population of echoes with small Doppler velocities with the opposite polarity to all other E-region velocities and to the expected plasma convection velocity component. The near ranges where these echoes were detected did not exceed a fixed value for all radar beams, with this value increasing with frequency. For example, Milan et al. (2004) presented an example of observations at $12 \mathrm{MHz}$ that showed that the maximum range where these echoes were observed was $405 \mathrm{~km}$, while at $14 \mathrm{MHz}$ this maximum range was $430 \mathrm{~km}$ (see their Fig. 1a). Milan et al. (2004) interpreted these echoes as backscatter from the high aspect angle echoes and termed them High Aspect angle Irregularity Region (HAIR) echoes. Our observations show a similar variation with range but velocity has the same polarity as all other E-region velocities, Fig. 7b. One should note that Milan et al. (2004) also presented examples of the HAIR echo observations by the Stokkseyri HF radar that showed the same velocity polarity, which is consistent with our results.

To study the HAIR-like echoes in further detail we analyze the dependence of Doppler velocity and spectral width upon range and beam number. We compare the trends with those seen for the regular E-region echoes detected at the same time. Figure 9 shows a time sequence of range-beam number plots on 14 April 2006 in 10-min intervals (rows) colour-coded in average velocity (first column) and spectral width (second column) as indicated on the right of the figure. The average velocity and spectral width for each range-beam cell were calculated using all echoes that were observed within that cell during the 10-min interval. Each calculation required a minimum of 2 measurements per interval. The range-beam cells with white horizontal lines indicate positive velocities.

The HAIR-like echoes can be identified in Fig. 9a as cells with velocities of up to $\simeq 170 \mathrm{~m} / \mathrm{s}$ at ranges $270-405 \mathrm{~km}$ that do not exhibit a significant variation with beam number. This is in sharp contrast with the E-region echoes at $405-720 \mathrm{~km}$ with velocities up to $300 \mathrm{~m} / \mathrm{s}$ that show a clear decrease in velocity with the beam number increasing. A clear drop in velocity was observed at ranges $360-405 \mathrm{~km}$. The location of the cell within the E-region band (taken to be between the ranges $405-630 \mathrm{~km}$ ) exhibiting the highest average velocity is indicated by a diamond in each plot; the value of which is shown in each panel as $V^{E}$. The velocity decreases as range increases/decreases from where velocity maximum is observed, e.g. in panel (d) in beam 0 velocity is smaller at $405 \mathrm{~km}$ or $585 \mathrm{~km}$ than at $495 \mathrm{~km}$ (where diamond is). This feature has been attributed in the past to the decrease in velocity with the aspect angle (Ogawa et al., 1980; Nielsen, 1986; Makarevitch et al., 2002b; Makarevich et al., 2006, 2007).

The spectral width was also enhanced at short ranges 270$405 \mathrm{~km}$ corresponding to the HAIR-like echoes in the second column of Fig. 9a as compared, for example, to the last frame, Fig. 9d. Similar HAIR-like echo bands were observed in the second and third frames with the HAIR-like echoes receding from the E-region band and showing a clear decrease in velocity and width with time so that in the fourth frame no HAIR band was observed.

As mentioned, the Doppler velocity at near ranges showed no clear trend with changing beam number. To analyze the variation in velocity of the HAIR-like echoes with time, the maximum velocity at these ranges was estimated by 


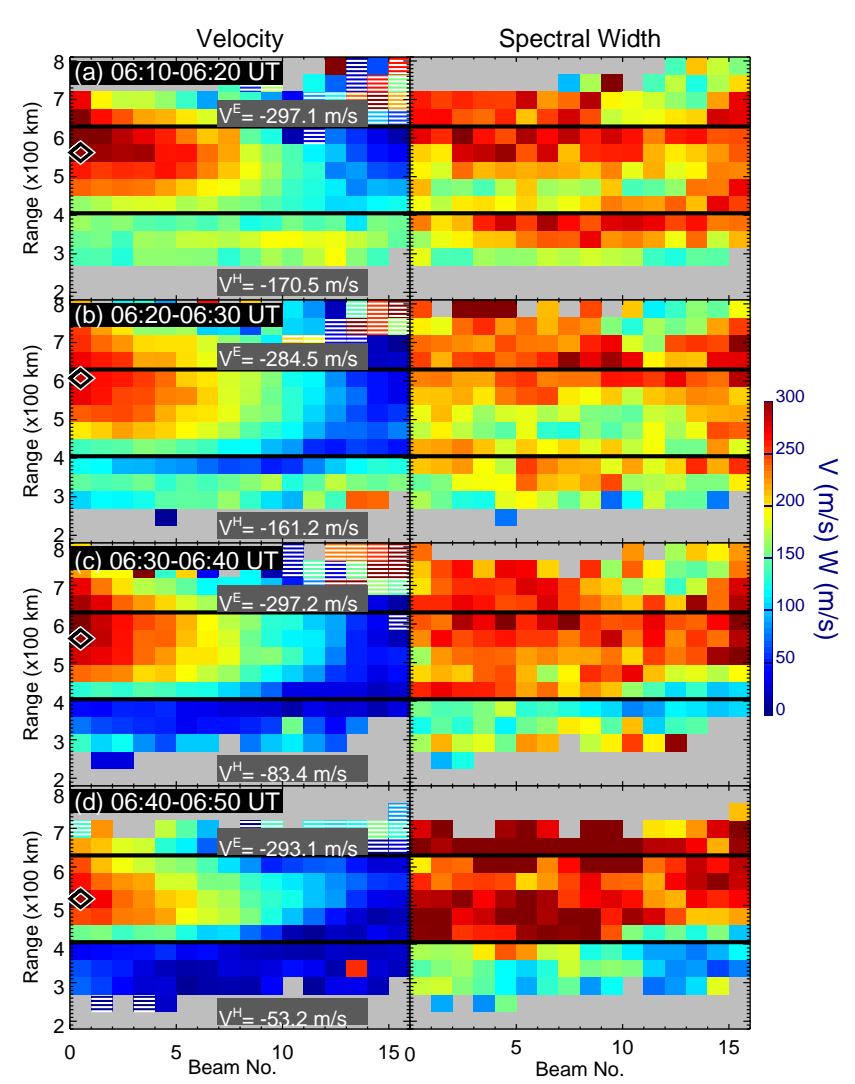

Fig. 9. Range versus beam plots for 4 selected 10-min frames (rows) on 14 April 2006 for the Bruny Island radar. The plots display the 10-min-averaged Doppler velocity (first column) and spectral width (second column) as specified on the right of the figure. The plot cells filled with solid colour (horizontal lines) correspond to the negative (positive) Doppler velocity. The horizontal black lines indicate the ranges of $405 \mathrm{~km}$ and $630 \mathrm{~km}$. The diamonds on the left show the range-beam cell with maximum velocity detected between these ranges. The maximum velocity value $V^{E}$ is displayed in each plot along with the mean maximum velocity at near ranges $V^{H}$ (see text for details).

considering the maximum velocities in each beam between the ranges $270-405 \mathrm{~km}$ and then averaging over all beams. The resulting value, $V^{H}$, is also displayed in each panel. This velocity is clearly decreasing from (a) to (d) accompanied by the corresponding decrease in spectral width. Figure 9 thus presents a clear example of the HAIR-like echoes disappearing from the near ranges with the E-region echoes only showing marginal changes in their velocity and width. One can conclude that the echoes with enhanced velocities and widths at near ranges are indeed a separate echo population.

Milan et al. (2004) proposed that the near-range echoes are generated at locations with significant non-zero aspect angles. Our modelling involving calculations of the geometric aspect angles demonstrated that the echoes were observed a few hundred $\mathrm{km}$ from the locations with small geometric aspect angles. Although our calculations of the real expected aspect angles showed that the ranges with small real angles were closer to the radar (green line in Fig. 1), to fully match the HAIR band with the $\alpha_{R}=0^{\circ}$ line would require a substantial peak electron density $\left(\sim 1.4 \times 10^{5} \mathrm{~cm}^{-3}\right)$. It is likely then that the near-range echoes were indeed coming from locations with considerably large real aspect angles. The fact that only the radar with poorer geometric aspect angles (Bruny Island) was observing the HAIR-like echoes also supports this interpretation.

Figure 9 also shows that the F-region echoes were observed at larger ranges $>\sim 630 \mathrm{~km}$. These echoes are easy to distinguish from their E-region counterparts by their opposite sense of Doppler velocities (positive velocities are shown by the cells with horizontal lines). The presence of F-region echoes for some frames in the period of interest presents a good opportunity to examine the ionospheric electric field conditions under which the HAIR-like echoes are observed. At these ranges radars measure the line-of-sight (l-o-s) component of the plasma drift velocity in the F-region. The maximum velocity within the F-region viewing area represents the lower limit on the local plasma convection speed and hence on the electric field magnitude. The electric fields estimated from the ranges corresponding to the F-region are not necessarily the same as those at the E-region ranges (e.g. because of variations with latitude). However, it is important to realize that the large differences between the E- and F-region 1-o-s velocities observed in Fig. 9, including opposite polarities measured in large-number beams, do not imply large differences between the convection velocities (i.e. shears) in the E- and F-region ranges. Thus using a similar experimental configuration, Makarevitch et al. (2004) demonstrated that, while there were some differences between the electric fields in the E- and F-region ranges as determined from the DMSP ion drift measurements, they were nowhere near enough to explain the factor of 5-6 between the E- and Fregion speeds inferred from the 1-o-s velocity observations from all 16 beams. This is simply a consequence of the fact that the E-region irregularity phase velocity is significantly different from the plasma convection 1-o-s velocity component (e.g. Makarevitch et al., 2004; Koustov et al., 2005).

Figure 10 shows (a) the range-time-intensity (RTI) plot of the Doppler velocity as measured in beam 14 of the Bruny Island radar and (b) the average irregularity phase velocity estimates for each 10-min frame between 03:00-08:00 UT on 14 April 2006. The three velocity estimates shown in panel (b) are magnitudes of the maximum F-region velocity $V^{F}$ divided by 2 (triangles), maximum E-region velocity $V^{E}$ (circles), and velocity of near-range HAIR-like echoes $V^{H}$ (diamonds). The $V^{E}$ and $V^{H}$ values were calculated from 10-min velocity range-beam plots analogous to Fig. 9 as described above. The calculation of both $V^{E}$ and $V^{H}$ required that for each 10-min interval, the number of filled range-beam cells with finite velocity values (i.e. cells that are not grey in Fig. 9) between the range intervals $405-630 \mathrm{~km}$ and $180-360 \mathrm{~km}$, respectively, exceeded $50 \%$. The values 
for $V^{F}$ were taken from the cell with the maximum velocity within the FoV between ranges $765-3015 \mathrm{~km}$ provided that the following criteria were met: (1) the cell contained 2 or more measurements and (2) the cell had a neighboring cell (in either range or beam) containing at least 1 measurement with a velocity less than $2000 \mathrm{~m} / \mathrm{s}$.

Figure 10a clearly shows that the HAIR-like echoes with enhanced velocities were detected between 05:30-06:30 UT at ranges $270-405 \mathrm{~km}$. This interval is marked by the dashed lines in Fig. 10. Throughout this interval and for a further $\sim 1 \mathrm{~h}$ ( 6 frames) after that, the data collected by the Bruny Island radar met the criteria suitable for the calculation of $V^{H}$ (diamonds in Fig. 10b) although it is clear that near-range velocity drops after 06:30 UT so that no actual HAIR echoes are detected after that (e.g. in Fig. 9d). Instead Fig. 10a shows that velocities at these ranges were very small and comparable to those of the E-region echoes in this beam. This is reflected in low values for $V^{H}$ after 06:30 UT. A completely different variation is observed for the E-region velocity $V^{E}$. It was close to $300 \mathrm{~m} / \mathrm{s}$ and stayed almost constant until 07:00 UT, dropping to less than $200 \mathrm{~m} / \mathrm{s}$, and then slowly increasing again. The F-region velocities $V^{F}$ varied quite dramatically starting at $\sim 600 \mathrm{~m} / \mathrm{s}$ at 03:00 UT, increasing to $\sim 1700 \mathrm{~m} / \mathrm{s}$ at $05: 00 \mathrm{UT}$, then decreasing to small values below $200 \mathrm{~m} / \mathrm{s}$ at 07:00 UT.

It appears from Fig. 10 that a decrease in $V^{H}$ and gradual disappearance of the HAIR echoes is associated with the drop in $V^{F}$ at 06:20-06:50 UT. Overall, the HAIR echoes appear to be associated with high F-region velocities exceeding $600 \mathrm{~m} / \mathrm{s}$. It should be also noted that the Bruny Island radar observes at relatively large angles with respect to magnetic L shells and hence the Doppler velocities measured by the Bruny Island radar with lowest L-shell angle of $\sim 55^{\circ}$ are likely to be representative of even larger plasma flow velocities by a factor of $1 / \cos 55^{\circ}=1.7$. This gives an estimate of $\sim 1000 \mathrm{~m} / \mathrm{s}$ for the plasma velocity required to drive the HAIR echoes at near ranges. Our observations thus suggest that high plasma velocities and hence high electric fields are required for the generation of the short-range HAIR-like echoes exhibiting enhanced velocities and spectral widths as compared to regular E-region backscatter observed at these ranges in other time intervals.

\section{Summary of findings}

In this paper, a statistical analysis of E-region echoes observed by the dual TIGER Bruny Island and Unwin HF radars over $\sim 2$-year period (November 2004-December 2006) was presented. The short-range echoes $(\leq 765 \mathrm{~km})$ were observed at magnetic latitudes $58^{\circ}-60^{\circ} \mathrm{S}$ under both quiet and disturbed geomagnetic conditions. Diurnal variation of the echo occurrence showed two peaks in the morning (03:00-09:00 MLT) and evening sectors (15:00-21:00 MLT) with the latter peak having smaller maximum and being

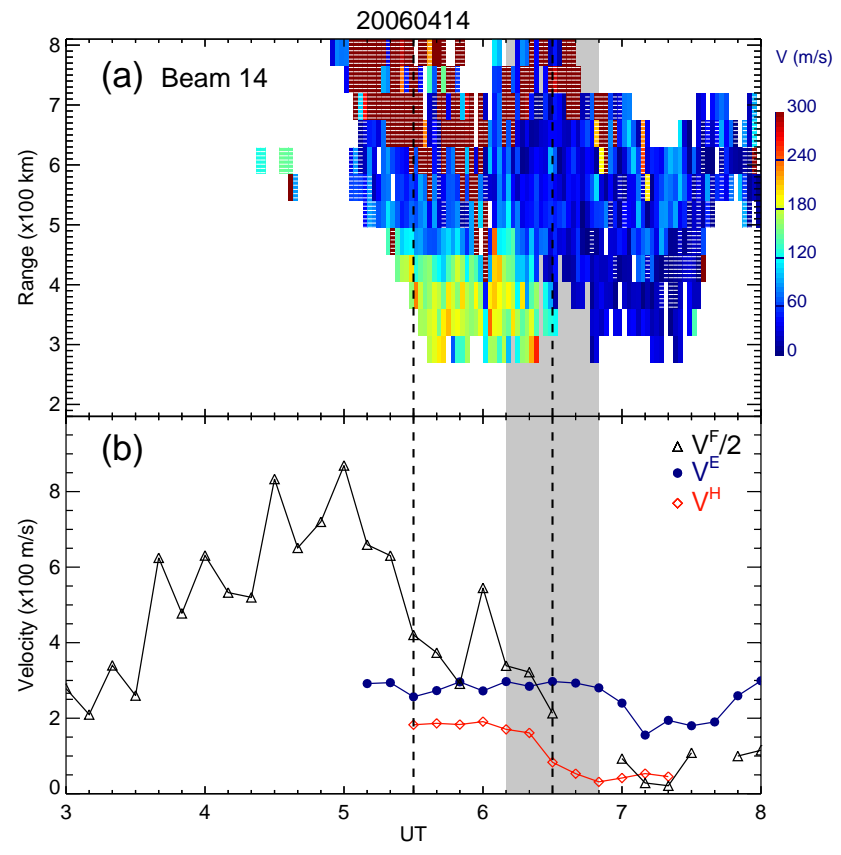

Fig. 10. Storm-time velocities measured by the Bruny Island radar on 14 April 2006. The top panel is a range-time-intensity (velocity) plot showing the Doppler velocity data in beam 14 . The colour scale is shown on the right again with cells filled with colour (horizontal lines) representing negative (positive) Doppler velocities. The bottom panel shows time variation of the maximum F-region velocity $V^{F}$ divided by 2 (triangles), maximum E-region velocity $V^{E}$ (circles), and mean maximum velocity at closer ranges $r \leq 405 \mathrm{~km}$ $V^{H}$ (diamonds). The dashed lines indicate the interval 05:3006:30 UT during which the HAIR-like echoes were observed. The grey rectangle corresponds to the 4 frames shown in Fig. 9 (06:1006:50 UT).

prominent only in some monthly periods. The echo occurrence was further investigated using the spatial distribution plots which showed a flat (i.e. nearly constant range) occurrence band at ranges $225-540 \mathrm{~km}$ in the morning sector throughout the entire 2-year dataset. In the evening sector, on the other hand, a substantial fraction of F-region echoes appeared at ranges exceeding $585 \mathrm{~km}$. An interesting new feature (i.e. a "curved" occurrence band) was observed in some months in the evening sector. This echo band was observed closer to (farther from) the Unwin radar in high-numbered (low-numbered) beams, with the opposite sense of curvature for the Bruny Island radar. It was found that the curved feature in the evening sector was observed during geomagnetic storms.

A comparison between the locations of the curved band and where geometric aspect angles reach their minimum demonstrated a reasonable agreement. This indicates that the E-region backscatter moves farther from the radar during geomagnetic storms in the evening sector as refraction becomes less significant, which appeared to disagree with 
previous studies. Further analysis involving ionosonde measurements of the E-region critical frequency $f_{0} E$ showed that the curved feature was observed when $f_{0} E$ was substantially lower than that during normal conditions. This happens later in the storm development cycle. Hence it was argued that it was possible to reconcile our results with those reported in previous studies, assuming that they were mostly obtained during the initial storm phase when densities were either enhanced or close to normal and refraction was more significant causing the scatter to move closer to the radar.

Different populations of E-region HF echoes were investigated. The population of echoes with low velocities and large range of spectral widths was a predominant feature in both radar datasets. A separate population of HF echoes was observed by both TIGER radars during geomagnetic storms. These echoes had negative velocities $\simeq 0-300 \mathrm{~m} / \mathrm{s}$ and relatively large widths $\simeq 100-350 \mathrm{~m} / \mathrm{s}$. The spectral width showed an increase as the Doppler velocity became more negative giving a characteristic "flare"-like shape in the width-versus-velocity plots. The flare was clearly associated with highly negative $D_{s t}$ values. The storm-time echoes were found in both TIGER radar datasets, but they displayed some noticeable differences between the radars. The population observed by the Unwin radar was similar to low-velocity echoes but with somewhat elevated velocities and width, most likely due to the higher electric field and turbulence levels during storm conditions. In the Bruny Island dataset, the storm-time echoes consisted of two distinct classes, one of which was similar to the storm-time echoes observed by the Unwin radar. The other class consisted of echoes that were observed at near ranges $(<405 \mathrm{~km})$ with fairly constant velocity across all beams. As such they were similar to the High Aspect angle Irregularity Region (HAIR) echoes reported previously for the Pykkvibear HF radar observations. It was found that both the Doppler velocity and the spectral width of these echoes were significantly elevated as compared to regular E-region echoes in these near ranges. The HAIR-like echoes appeared to be associated with periods of very strong plasma convection.

\section{Conclusions}

The E-region echoes from sub-auroral latitudes are observed in bands centered around the ranges where radio waves reach orthogonality with the magnetic field. The band center range and the band curvature are representative of the ionospheric E-region electron density with both decreasing with increasing electron density. An extreme case is observed in the evening sector during geomagnetic storms when the curved band is observed close to the locations where geometric aspect angle is zero. The low-velocity echoes dominate the E-region backscatter. During geomagnetic storms, HF radars may observe a separate storm-time echo population consisting of E-region echoes whose spectral width increases with phase velocity. In addition, HF radars with relatively poor geometric aspect angles may observe the near-range HAIRlike echoes $(<405 \mathrm{~km})$ with enhanced velocity and spectral width when the electron density is low and when the ionospheric electric field is particularly high.

Acknowledgements. This research was supported by the Australian Research Council (ARC) Discovery grant to R. A. M. (project DP0770366). TIGER is supported by a consortium of institutions: La Trobe University, Monash University, University of Newcastle, Australian Government Antarctic Division, ISR Division DSTO and IPS Radio and Space Services. Financial support has been given by the ARC, Victorian Partnership for Advanced Computing, British Antarctic Survey, USAF Office of Scientific Research and RLM Systems Pty Ltd. The Macquarie Island and the Hobart Ionosondes are operated by the Ionospheric Prediction Service (IPS). We would like to thank T. A. Kane for help regarding the F-region maximum velocity estimates. The authors thank both referees for their positive criticism and suggestions. Fruitful discussions with J.-P. St.-Maurice, J. M. Ruohoniemi, T. Ogawa, and A. V. Koustov are also kindly acknowledged.

Topical Editor M. Pinnock thanks P. T. Jayachandran and J.P. St-Maurice for their help in evaluating this paper.

\section{References}

Brown, G. M. and Wynne, R.: Magnetic disturbance effects in the E region of the ionosphere, J. Atmos. Terr. Phys., 25, 651-656, 1977.

Chisham, G., Lester, M., Milan, S. E., Freeman, M. P., Bristow, W. A., Grocott, A., McWilliams, K. A., Ruohoniemi, J. M., Yeoman, T., Dyson, P. L., Greenwald, R. A., Kikuchi, T., Pinnock, M., Rash, J. P. S., Sato, N., Sofko, G. J., Villain, J.P., and Walker, A. D. M.: A decade of the Super Dual Auroral Radar Network (SuperDARN): scientific achievements, new techniques and future directions, Surv. Geophys., 28, 33-109, doi:10.1007/s10712-007-9017-8, 2007.

Drexler, J., St.-Maurice, J.-P., Chen, D., and Moorcroft, D. R.: New insights from a nonlocal generalization of the Farley-Buneman instability problem at high latitudes, Ann. Geophys., 20, 20032025, 2002, http://www.ann-geophys.net/20/2003/2002/.

Dyson, P. L. and Devlin, J. C.: The Tasman International Geospace Environment Radar, The Physicist (The Australian Institute of Physics), 37, 48-53, 2000.

Eglitis, P., Robinson, T. R., McCrea, I. W., Schlegel, K., Nygren, T., and Rodger, A. S.: Doppler spectrum statistics obtained from three different-frequency radar auroral experiments, Ann. Geophys., 13, 56-65, 1995, http://www.ann-geophys.net/13/56/1995/.

Farley, D. T.: Theory of equatorial electrojet plasma waves: new developments and current status, J. Atmos. Terr. Phys., 47, 729744, 1985.

Fejer, B. G. and Kelley, M. C.: Ionospheric irregularities, Geophys. Rev., 18, 401-454, 1980.

Fukumoto, M., Nishitani, N., Ogawa, T., Sato, N., Yamagishi, H., and Yukimatu, A.: Statistical analysis of echo power, Doppler velocity and spectral width obtained with the Syowa South HF radar, Adv. Polar Upper Atmos. Res., 13, 37-47, 1999. 
Greenwald, R. A., Ecklund, W. L., and Balsley, B. B.: Radar observations of auroral electrojet currents, J. Geophys. Res., 80, 3635-3641, 1975.

Greenwald, R. A., Baker, K. B., Dudeney, J. R., Pinnock, M., Jones, T. B., Thomas, E. C., Villain, J.-P., Cerisier, J.-C., Senior, C., Hanuise, C., Hunsuker, R. D., Sofko, G., Koehler, J., Nielsen, E., Pellinen, R., Walker, A. D. M., Sato, N., and Yamagishi, H.: DARN/SuperDARN: A global view of the dynamics of highlatitude convection, Space Sci. Rev., 71, 763-796, 1995.

Haldoupis, C.: A review on radio studies of auroral E region ionospheric irregularities, Ann. Geophys., 7, 239-258, 1989, http://www.ann-geophys.net/7/239/1989/.

Haldoupis, C., Bourdillon, A., Six, M., and Delloue, J.: Midlatitude E region coherent backscatter observed simultaneously at two HF radar frequencies, J. Geophys. Res., 101(A4), 7961-7972, 1996.

Hall, G. E., MacDougall, J. W., Moorcroft, D. R., St.-Maurice, J.P., Manson, A. H., and Meek, C. E.: Super Dual Auroral Radar Network observations of meteor echoes, J. Geophys. Res., 102, 14603-14614, doi:10.1029/97JA00517, 1997.

Hamza, A. M. and St.-Maurice, J.-P.: A turbulent theoretical framework for the study of current-driven $E$ region irregularities at high latitudes: Basic derivation and application to gradient-free situations, J. Geophys. Res., 98, 11587-11599, 1993.

Hanuise, C.: High latitude ionospheric irregularities, Radio Sci., 18, 1093-1121, 1983.

Hanuise, C., Villain, J.-P., Cerisier, J. C., Senior, C., Ruohoniemi, J. M., Greenwald, R. A., and Baker, K. B.: Statistical study of high-latitude E region Doppler spectra obtained with SHERPA HF radar, Ann. Geophys., 9, 273-285, 1991, http://www.ann-geophys.net/9/273/1991/.

Kane, R. P.: Effect of geomagnetic storms on the electron density of the ionospheric E-region at mid-latitudes, Planet. Space Sci., 41, 161-162, 1979.

Koustov, A. V., Igarashi, K., André, D., Ohtaka, K., Sato, N., Yamagishi, H., and Yukimatu, A.: Observations of 50- and 12-MHz auroral coherent echoes at the Antarctic Syowa station, J. Geophys. Res., 106, 12875-12887, 2001.

Koustov, A. V., Danskin, D. W., Uspensky, M. V., Ogawa, T., Janhunen, P., Nishitani, N., Nozawa, S., Lester, M., and Milan, S.: Velocities of auroral coherent echoes at 12 and $144 \mathrm{MHz}$, Ann. Geophys., 20, 1647-1661, 2002, http://www.ann-geophys.net/20/1647/2002/.

Koustov, A. V., Danskin, D. W., Makarevitch, R. A., and Gorin, J. D.: On the relationship between the velocity of E-region HF echoes and $\boldsymbol{E} \times \boldsymbol{B}$ plasma drift, Ann. Geophys., 23, 371-378, 2005, http://www.ann-geophys.net/23/371/2005/.

Makarevich, R. A. and Dyson, P. L.: Dual HF radar study of the subauroral polarization stream, Ann. Geophys., 25, 2579-2591, 2007, http://www.ann-geophys.net/25/2579/2007/.

Makarevich, R. A., Senior, A., Koustov, A. V., Uspensky, M. V., Honary, F., and Dyson, P. L.: A study of aspect angle effects in the $E$-region irregularity velocity using multi-point electric field measurements, Geophys. Res. Lett., 33, L21102, doi:10.1029/ 2006GL027740, 2006.

Makarevich, R. A., Koustov, A. V., Senior, A., Uspensky, M., Honary, F., and Dyson, P. L.: Aspect angle dependence of the E-region irregularity velocity at large flow angles, J. Geophys. Res., 112, A11303, doi:10.1029/2007JA012342, 2007.

Makarevitch, R. A., Ogawa, T., Igarashi, K., Koustov, A. V., Sato,
N., Ohtaka, K., Yamagishi, H., and Yukimatu, A.: On the power-velocity relationship for $12-$ and $50-\mathrm{MHz}$ auroral coherent echoes, J. Geophys. Res., 106, 15455-15470, 2001.

Makarevitch, R. A., Koustov, A. V., Igarashi, K., Sato, N., Ogawa, T., Ohtaka, K., Yamagishi, H., and Yukimatu, A. S.: Comparison of flow angle variations of E-region echo characteristics at VHF and HF, Adv. Polar Upper Atmos. Res., 16, 59-83, 2002a.

Makarevitch, R. A., Koustov, A. V., Sofko, G. J., André, D., and Ogawa, T.: Multifrequency measurements of HF Doppler velocity in the auroral E region, J. Geophys. Res., 107, 1212, doi: 10.1029/2001JA000268, 2002b.

Makarevitch, R. A., Honary, F., and Koustov, A. V.: Simultaneous HF measurements of E- and F-region Doppler velocities at large flow angles, Ann. Geophys., 22, 1177-1185, 2004, http://www.ann-geophys.net/22/1177/2004/.

Meyer, M. G., Sahr, J. D., and Morabito, A.: A statistical study of subauroral $E$ region coherent backscatter observed near $100 \mathrm{MHz}$ with passive radar, J. Geophys. Res., 109, A07308, doi: 10.1029/2004JA010396, 2004.

Milan, S. E. and Lester, M.: A classification of spectral populations observed in HF radar backscatter from the E region auroral electrojets, Ann. Geophys., 19, 189-204, 2001, http://www.ann-geophys.net/19/189/2001/.

Milan, S. E., Lester, M., and Sato, N.: Multi-frequency observations of E-region HF radar aurora, Ann. Geophys., 21, 761-777, 2003, http://www.ann-geophys.net/21/761/2003/.

Milan, S. E., Lester, M., Yeoman, T. K., Robinson, T. R., Uspensky, M. V., and Villain, J.-P.: HF radar observations of high-aspect angle backscatter from the E-region, Ann. Geophys., 22, 829847, 2004, http://www.ann-geophys.net/22/829/2004/.

Moorcroft, D. R.: Outstanding issues in the theory of radar aurora: Evidence from the frequency dependence of spectral characteristics, J. Geophys. Res., 107, 1301, doi:10.1029/2001JA009218, 2002.

Nielsen, E.: Aspect angle dependence of mean Doppler velocities of 1-m auroral plasma waves, J. Geophys. Res., 91, 10173-10177, 1986.

Nielsen, E., del Pozo, C. F., and Williams, P. J. S.: VHF coherent radar signals from the $\mathrm{E}$ region ionosphere and the relationship to electron drift velocity and ion acoustic velocity, J. Geophys. Res., 107, 1012, doi:10.1029/2001JA900111, 2002.

Ogawa, T., Balsley, B. B., Ecklund, W. L., Carter, D. A., and Johnston, P. E.: Aspect angle dependence of irregularity phase velocities in the auroral electrojet, Geophys. Res. Lett., 7, 1081-1084, 1980.

Ogawa, T., Nishitani, N., Sato, N., Yamagishi, H., and Yukimatu, A. S.: E region echoes observed with the Syowa HF radar under disturbed geomagnetic conditions, Adv. Polar Upper Atmos. Res., 16, 84-98, 2002.

Ponomarenko, P. V. and Waters, C. L.: Spectral width of SuperDARN echoes: measurement, use and physical interpretation, Ann. Geophys., 24, 115-128, 2006, http://www.ann-geophys.net/24/115/2006/.

Sahr, J. and Fejer, B. G.: Auroral electrojet plasma irregularity theory and experiment: A critical review of present understanding and future directions, J. Geophys. Res., 101, 26893-26909, 1996.

Schlegel, K., Thomas, E. C., and Ridge, D.: A statistical study of auroral radar spectra obtained with SABRE, J. Geophys. Res., 
91, 13483-13492, 1986.

Uspensky, M. V., Kustov, A. V., Sofko, G. J., Koehler, J. A., Villain, J.-P., Hanuise, C., Ruohoniemi, J. M., and Williams, P. J. S.: Ionospheric refraction effects in slant range profiles of auroral HF coherent echoes, Radio Sci., 29, 503-517, 1994.
Watermann, J., McNamara, A. G., Sofko, G. J., and Koehler, J. A.: Distribution of mean Doppler shift, spectral width and skewness of coherent 50-MHz auroral radar backscatter, J. Geophys. Res., 94, 6979-6985, 1989. 